\title{
Experimental and CPFD study of gas-solid flow in a cold pilot calciner
}

Nakhaei, Mohammadhadi; Hessel, Christian Evald; Wu, Hao; Grévain, Damien; Zakrzewski, Sam; Jensen, Lars Skaarup; Glarborg, Peter; Dam-Johansen, Kim

Published in:

Powder Technology

Link to article, DOI:

10.1016/j.powtec.2018.09.008

Publication date:

2018

Document Version

Peer reviewed version

Link back to DTU Orbit

Citation (APA):

Nakhaei, M., Hessel, C. E., Wu, H., Grévain, D., Zakrzewski, S., Jensen, L. S., Glarborg, P., \& Dam-Johansen, K. (2018). Experimental and CPFD study of gas-solid flow in a cold pilot calciner. Powder Technology, 340, 99115. https://doi.org/10.1016/j.powtec.2018.09.008

\section{General rights}

Copyright and moral rights for the publications made accessible in the public portal are retained by the authors and/or other copyright owners and it is a condition of accessing publications that users recognise and abide by the legal requirements associated with these rights.

- Users may download and print one copy of any publication from the public portal for the purpose of private study or research.

- You may not further distribute the material or use it for any profit-making activity or commercial gain

- You may freely distribute the URL identifying the publication in the public portal 


\section{Accepted Manuscript}

Experimental and CPFD study of gas-solid flow in a cold pilot calciner

Mohammadhadi Nakhaei, Christian Evald Hessel, Hao Wu, Damien Grévain, Sam Zakrzewski, Lars Skaarup Jensen, Peter Glarborg, Kim Dam-Johansen

PII:

S0032-5910(18)30735-6

DOI: doi:10.1016/j.powtec.2018.09.008

Reference: PTEC 13682

To appear in:

Powder Technology

Received date:

5 May 2018

Revised date:

30 August 2018

Accepted date:

5 September 2018

Please cite this article as: Mohammadhadi Nakhaei, Christian Evald Hessel, Hao Wu, Damien Grévain, Sam Zakrzewski, Lars Skaarup Jensen, Peter Glarborg, Kim DamJohansen, Experimental and CPFD study of gas-solid flow in a cold pilot calciner. Ptec (2018), doi:10.1016/j.powtec.2018.09.008

This is a PDF file of an unedited manuscript that has been accepted for publication. As a service to our customers we are providing this early version of the manuscript. The manuscript will undergo copyediting, typesetting, and review of the resulting proof before it is published in its final form. Please note that during the production process errors may be discovered which could affect the content, and all legal disclaimers that apply to the journal pertain. 
Experimental and CPFD study of gas-solid flow in a cold pilot calciner

Mohammadhadi Nakhaei ${ }^{\mathrm{a},{ }^{*}}$ mnak@kt.dtu.dk, Christian Evald Hessel ${ }^{\mathrm{a}}$, Hao Wu ${ }^{\mathrm{a}, *}$, Damien Grévain $^{\mathrm{b}}$, Sam Zakrzewski ${ }^{\mathrm{b}}$, Lars Skaarup Jensen ${ }^{\mathrm{b}}$, Peter Glarborg ${ }^{\mathrm{a}}$, Kim Dam-Johansen ${ }^{\mathrm{a}}$

${ }^{\text {a }}$ Technical University of Denmark, Department of Chemical and Biochemical Engineering, Lyngby Campus, 2800 Kgs. Lyngby, Denmark

${ }^{\mathrm{b}}$ FLSmidth A/S, Cement R\&D, Vigerslev Alle 77, 2500 Valby, Denmark

${ }^{*}$ Corresponding author. 


\section{Abstract}

Experimental characterization and computational fluid particle dynamics (CPFD) simulations of a cold pilot-scale cement calciner were carried out to investigate the dispersion and heating of cold cement raw meal particles in the hot gas flow. During the experiments, the gas velocity and temperature were measured at different locations upstream and downstream of the place where the particles were fed to the calciner. The simulations were carried out using Eulerian-Lagrangian approach together with the Multi-Phase Particle-In-Cell (MP-PIC) method, based on the commercially available Barracuda Virtual Reactor ${ }^{\circledR}$ 17.1.0 software. For the particle-free flow, it was shown that the grid-independent velocity profiles predicted from the simulations are in proper agreement with the measured values. For the particle-laden flow, the simulation results from two drag models of EMMS and Gidaspow were compared with the gas temperature measurements and visual observations. The simulation results from the Gidaspow model exhibited an over-prediction of the amount of falling particles to the upstream regions. Both drag models exhibited a local minimum temperature region at a location slightly different from the measured one in a cross-section close to the particle feed position. For the Gidaspow model, a second low gas temperature region was observed at the opposite position of the particle feed that was not detected by the measurements. Overall, it is concluded that the Barracuda Virtual Reactor ${ }^{\circledR}$ software is able to capture the particle dispersion and gas-solid interactions in the studied pilot-scale calciner and the EMMS drag model is more reliable for prediction of the gas-solid flow.

Keywords: cement calciner gas-solid flow computational particle fluid dynamics drag model heat transfer 


\section{Nomenclature}

$C_{p_{p}} \quad$ Particle specific heat

$C_{D} \quad$ Drag coefficient

$d_{p} \quad$ Particle diameter

$d_{S M} \quad$ Sauter-mean diameter

$\mathbf{F}_{\mathbf{p}} \quad$ Particle feed-back term in the fluid momentum equation

$\mathbf{F}_{\mathbf{T} p} \quad$ Particle feed-back term in the fluid energy equation

g Gravitational acceleration vector

$h_{g} \quad$ Gas enthalpy

$N u_{p} \quad$ Particle Nusselt number

$P \quad$ Gas static pressure

$\operatorname{Pr}_{g} \quad$ Gas Prandtl number

$R e_{p} \quad$ Particle Reynolds number, $\frac{\rho_{g} d_{p} U_{s i p}}{\mu_{g}}$

$T_{g} \quad$ Gas temperature

$T_{p} \quad$ Particle temperature

$\mathbf{u}_{g} \quad$ Gas velocity vector

$\mathbf{u}_{p} \quad$ Particle velocity vector

$U_{\text {slip }} \quad$ Slip velocity, $\left|\mathbf{u}_{g \odot p}-\mathbf{u}_{p}\right|$

$\mathbf{x}_{p} \quad$ Particle position vector 
Greek symbols

$\Delta \quad$ LES filter width

$\delta_{i j} \quad$ Kronecker delta

$\theta_{g} \quad$ Gas volume fraction

$\theta_{C P} \quad$ Close-pack particle volume fraction

$\theta_{p} \quad$ Particle volume fraction

$\kappa_{\text {eff }} \quad$ Effective thermal conductivity, $\kappa_{t}+\kappa_{g}$

$\kappa_{g} \quad$ Gas thermal conductivity

$\kappa_{t} \quad$ Turbulent thermal conductivity

$\mu_{\text {eff }} \quad$ Gas effective viscosity, $\mu_{t}+\mu_{g}$

$\mu_{g} \quad$ Gas molecular viscosity

$\mu_{t} \quad$ Turbulent viscosity

$\rho_{g} \quad$ Gas density

$\rho_{p} \quad$ Particle density

$\tau_{N S} \quad$ Particle normal stress

$\tau_{p} \quad$ Particle inertial response time, $\frac{\rho_{p} d_{p}^{2}}{18 \mu_{g}}$

$\tau_{T} \quad$ Particle thermal response time, $\frac{C_{p_{p}} \rho_{p} d_{p}^{2}}{12 \kappa_{g}}$

Symbols

\langle\rangle$\quad$ Time-averaged value

$\odot p \quad$ Interpolated value from the Eulerian grid to the particle position 


\section{Introduction}

The cement industry is growing world-wide and the global yearly cement production has increased from around 1.5 billion tonnes in 1996 to around 4.2 billion tonnes in 2016 [1, 2]. Along with the increasing demand for cement, two important aspects have been considered for improvement in the cement ind ustry: reduction of emissions such as $\mathrm{NOx}$ and $\mathrm{CO} 2$, and reduction of the operational costs, e.g. by increasing thermal efficiency and decreasing fuel cost.

The cement calciner is an important compartment of the cement plant. In this compartment, the endothermic calcination reaction, i.e. thermal decomposition of calcium carbonate to calcium oxide, takes place. Around 55 to 65 percent of the fuel consumption of a cement plant is used in the calciner [3]. The calcination process affects different parameters such as the cement quality, the amount of fuel consumption and the emissions [4]. In a calciner, the temperature of the gas-solid mixture should be sufficiently high so that the calcination reaction is not limited by thermodynamic equilibrium. At the same time, local high temperature (above $1100^{\circ} \mathrm{C}$ ) regions should be avoided in order to prevent melt-induced build-up formation [5]. An important parameter affecting the temperature distribution in a calciner is the mixing behaviour of the raw meal particles with the carrier gas. Uneven dispersion of raw meal particles can lead to local high (low) particle volume fraction regions which can in turn cause low (high) temperature regions in a calciner.

Among different types of calciners, controlling the gas-solid dispersion becomes more complicated for in-line calciners (ILC) due to the presence of recirculation regions in the gas-solid flow [6, 7]. In an ILC system, the hot flue gas is directly led to the bottom of the calciner while an extra amount of combustion air, i.e. tertiary air, is fed to the calciner at a downstream 
location. The raw meal and fuel can be added at different locations of the ILC systems. The gas-solid flow in an ILC can be studied both through conducting experiments and by performing computational fluid dynamics (CFD) simulations. Experimental studies of full- and pilot-scale calciners with the purpose of investigation of gas-solid interactions are rare. Most published research regarding full-scale measurements report the temperature or other parameters such as the degree of conversion, gas velocity, calcination degree, etc., only at the exit of the calciner [8-10] or at selected points across the calciner height $[11,12]$. These full-scale measurements were used only for validation of reactive calciner CFD models and were not able to demonstrate the details of gas-solid interactions (e.g. particle dispersion, gas-solid heat transfer and energy coupling, etc.) in calciners. The studied pilot scale calciners (see [13, 14] for riser calciners and [15] for bubbling fluidised bed calciner) are typically part of other process systems (e.g. calcium looping process) and the calciner operational condition is different from that of an ILC in a cement plant. There are also a few reported lab-scale studies investigating operational conditions of ILC systems by mimicking the gas-solid flow inside them as a liquid flow [16, 17]. However, these experiments are limited to qualitative study and visual observations of fuel-air mixing in the scaled down systems.

Another tool to investigate the gas-solid flow behaviour in cement calciners is to carry out CFD simulations. Generally, there are two main approaches for simulation of dilute and dense gas-solid systems: the Eulerian-Eulerian (EE) approach which considers the solid particles as a continuum medium, and the Eulerian-Lagrangian (EL) approach that tracks individual (clouds of) particles in time. In the EE method, additional closure terms are required in the solid phase equations to account for particle-particle and particle-wall interactions. For the case of distributed particle size, separate momentum and continuity equations should be solved for each size bin 
which makes the EE method challenging from modelling and computational cost points of view $[18,19]$. On the other hand, in the EL approach, a particle size distribution can be applied for the dispersed phase and the particle-particle and particle-wall interactions are directly resolved. However, for industrial systems where the total loading of particles is high, the particle-particle interactions in the EL method become computationally expensive. One of the solutions to this drawback of the EL method is the Multi-Phase Particle-In-Cell (MP-PIC) method, which models the particle-particle interactions by employing a particle stress term in the equation of particles motion [20, 21]. The MP-PIC method has been successfully implemented in simulating gas-solid flows in coal gasifier systems [22], pneumatic conveying flows [23], and fluidized beds [24-26].

Both EE [27-29] and EL [6, 7, 30] approaches have been used in the previous CFD studies; investigating gas-solid interactions and particle dispersion in calciners. Only a few of these studies have compared the simulation results with experimental data $[6,7,31]$ and the comparisons were carried out only to a limited extent. For reactive calciner studies, the EL method is used more frequently $[4,8,9,32-36]$ than the EE method [13]. To the authors' best knowledge, only conventional EE and EL methods have been applied to study cement calciners and application of the MP-PIC method has not been explored.

A phenomenon that significantly affects particle dispersion in a gas-solid flow is the drag force and it should be properly modelled in the CFD solver. The conventional drag models from Gidaspow [37] and Wen and $\mathrm{Yu}$ [38] consider homogeneo us particles properties in the flow and neglect the effect of clusters of particles that can affect the gas-solid flow significantly. A recently established method aiming to overcome this drawback is the Energy-Minimization-Multi-Scale (EMMS) approach [39]. However, the use of EMMS approach in CFD simulations of calciners (see [13]) is still limited and further exploration of applying the EMMS drag models to simulate 
calciner systems with heterogeneous particle properties is needed.

In the present study, a non-reactive gas-solid flow in a pilot-scale calciner is experimentally evaluated through extensive gas velocity and temperature measurements at different cross-sections. A computational particle fluid dynamics (CPFD) model is adopted to simulate the gas-solid flow in the pilot-scale calciner using the Eulerian-Lagrangian MP-PIC approach and validated against the measurement data. Important mechanisms affecting the dispersion and heat transfer between particles and the carrier gas are identified and evaluated for the two selected drag models of Gidaspow [37] and EMMS [39].

\section{Experimental apparatus}

In this section, the experimental setup, working conditions, and measurement methods of the cold pilot calciner are described.

\subsection{Geometry and working conditions}

The geometry of the cold pilot scale calciner is depicted in Fig. 1 with an illustration of different compartments. The calciner is composed of a main vertical vessel (calciner vessel) of $700 \mathrm{~mm}$ diameter. At the bottom, the calciner vessel is connected to a $400 \mathrm{~mm}$ diameter vertical riser pipe through a conical section. The riser pipe is connected to another pipe of a smaller diameter with two 90 degrees bends, i.e. the hot air pipe. This pipe is connected to a heat exchanger which supplies hot air to the system. It is possible to feed solid particles to the system in the middle of the calciner vessel through a $75 \mathrm{~mm}$ diameter slanted pipe and then a spreader box. The calciner vessel and also the raw meal feed pipe are made of transparent acrylic glass; so it is possible to visualize the behaviour of gas-solid flow inside these compartments. At the top of the calciner 
vessel, there is a 180 degrees swan neck connected to the calciner through a converging conical part. The gas-solid mixture exits the calciner through this part. The detailed geometrical drawings of the pilot calciner are provided in the supplementary material (section 1).

Figure 1: Front and side views of the cold-pilot calciner geometry. The different sections of the pilot, gas and particle inlets and outlet, and also the measurement planes are shown in the pictures.

The raw meal particles studied here are composed of approximately $80 \mathrm{wt} . \%$ calcium carbonate and the rest is a mixture of different materials such as silicone oxide, aluminium oxide, etc. In cement production, the raw meal material is usually milled and/or ground to a specific size with a top size of approximately $200 \mu m$ [5]. During the initial tests using the original size distribution of the received raw meal particles, the visual observation of particles was limited due to sticking of particles to the transparent walls. Therefore, the original raw meal material was filtered using a cyclone separator in order to remove the smaller sized particles. Besides removing the sticking particles effect, after increasing the size of particles, the fluidization was also improved and droppage of the particles to the riser pipe was diminished. The particle size distribution (PSD) of the tested raw meal material, measured using a Malvern Sirocco Mastersizer 2000 apparatus in dispersed (wet) condition, is depicted in Fig. 2. The Sauter mean diameter of the particles after filtering was around $d_{S M}=19.5 \mu \mathrm{m}$ (equivalent to a median diameter of $48.7 \mu \mathrm{m}$ ) which indicates that the tested particles lie in a region between group A and C in the Geldart's classification graph [40]. It should be noted that the original raw meal particles belonged to group C. For this group, the inter-particle forces are dominant compared to aerodynamic forces and as a 
result, the fluidization process was hindered.

Figure 2: Particle size distribution of the studied raw meal using laser diffraction method in a wet (water) dispersion. The distributions are based on averaged values of 5 sample measurements.

The experiments have been conducted for a controlled air flow rate of $1.2 \mathrm{~m}^{3} / \mathrm{s}$ while the temperature of the gas at the entrance of the calciner vessel (exit of the riser pipe) was set to $80^{\circ} \mathrm{C}$. The gas temperature for the control system was measured using a single thermocouple. The position of this thermocouple is shown in Fig. 1. The volumetric flow rate at this temperature corresponds to a mass flow rate of $1.285 \mathrm{~kg} / \mathrm{s}$. The air flow rate was measured using a venturi placed upstream of the heat exchanger. The air temperature and pressure at the venturi were stable at approximately $66^{\circ} \mathrm{C}$ and $1 \mathrm{~atm}$, respectively. The air temperature at the entrance of the calciner vessel was chosen in a way that the heat exchanger works in a stable condition. Furthermore, the temperature difference between the raw meal particles and the air flow would be sufficiently high to study the particle distribution through gas temperature measurements. The temperature at which the air leaves the heat exchanger was around $86^{\circ} \mathrm{C}$; but due to heat transfer losses from the walls, the air flow temperature reached a value of $80^{\circ} \mathrm{C}$ at the calciner vessel entrance (position of the thermocouple sensor in the control system).

The rate at which the filtered raw meal particles were fed to the pilot calciner was chosen to be equal to $500 \mathrm{~kg} / \mathrm{h}$. Before entering the calciner, the particles were placed in a raw meal vessel and were fed gradually to the system. It took around 58 minutes to run the system before the raw meal in this vessel was consumed; so each set of experiments has been conducted for a period shorter than 58 minutes. The raw meal particles temperature in the vessel was measured to be in 
the range of $24-32^{\circ} \mathrm{C}$. The operating conditions of the cold pilot calciner are summarized in Table 1.

Table 1: The experimental operating conditions of the cold pilot calciner.

\begin{tabular}{|l|c|c|}
\hline & Air flow at the calciner entrance & Particle flow \\
\hline Volumetric flow rate $\left(\mathrm{m}^{3} / \mathrm{s}\right)$ & 1.200 & - \\
\hline Mass flow rate $(\mathrm{kg} / \mathrm{s})$ & 1.285 & 0.139 \\
\hline Temperature $(\mathrm{C})$ & 80 & $24-32$ \\
\hline
\end{tabular}

\subsection{Measurement procedures and methods}

\subsubsection{Velocity measurements}

In order to understand the turbulent flow behaviour upstream of the region where the mixing of particles and the gas takes place, the vertical component of the gas velocity is measured at a horizontal plane $375 \mathrm{~mm}$ upstream of the reference point (refer to Fig. 1), i.e. z-375 plane. A TESTO 400 anemometer connected to a telescopic handle is used for this purpose. The accuracy of measurements for the velocity range of $0.6-40 \mathrm{~m} / \mathrm{s}$ and temperature range of $-30-140^{\circ} \mathrm{C}$ is \pm $0.2 \mathrm{~m} / \mathrm{s}$ and the response time is 0.5 seconds.

A disadvantage of this measurement tool is that it cannot measure the gas velocity accurately in dusty conditions. Hence, the gas vertical velocity is measured without feeding of the raw meal particles to the system. According to visual observations during the experiments, when the raw meal particles are added to the system, only a small amount of raw meal particles would travel in the downward direction to be present at the plane of velocity measurement. Therefore for this plane, it can be stated that the momentum coupling between the gas and the particles is 
insignificant and the velocity profiles at this position do not change significantly compared to the particle-free case.

The measurements have been conducted for 60 points in the mentioned cross-section, divided into 4 sets of 15 measurements across straight lines. The lines are diagonals of the cross-section positioned with lateral angles of 45 degrees from each other. For each measurement point, the measurements are carried out and averaged for a period of 60 seconds. The gas velocity measurement points are shown in Fig. 3 (top side).

\subsubsection{Temperature measurements}

For particle-laden flow, the gas temperature in different cross-sections of the calciner vessel is measured using a dynamic temperature sensor tool. This tool is composed of a $700 \mathrm{~mm}$ long polymer pipe that holds fifteen PT100 temperature sensors on its exterior surface. The temperature sensors are faced in the downward direction. The sensors are placed with $50 \mathrm{~mm}$ intervals except for the ones at both ends that are placed $40 \mathrm{~mm}$ away from their neighbouring sensor. After placing the temperature sensors, the openings in the polymer rod are sealed using silicone filling.

The temperature rod is hanged horizontally in the calciner vessel using a vertical steel pipe connected to its midpoint. By rotating this vertical pipe, it is possible to measure the gas temperature at different positions of a horizontal cross-section of the pilot calciner. Also it is possible to move the temperature sensors in the vertical direction using this steel pipe.

For each position of the polymer rod, the temperature measurements are recorded for a period of 180 seconds with a frequency of $0.1 \mathrm{~Hz}$. It should be noted that the recording time is started after reaching a semi-steady state behaviour by monitoring the meas ured temperature. The gas temperature is measured in 5 horizontal cross-sections of the calciner vessel at vertical 
positions of $-100,0,100,400$, and $800 \mathrm{~mm}$ in relation to the reference position. The measurement planes are shown in Fig. 1. These planes are addressed as z-100, z000, z+100, z+400, and z+800, respectively. For each cross-section, the measurements are performed for 6 angular positions of the temperature sensor rod equivalent to 90 points measurements at different positions of a cross-section in total. The overview of measurement points in each cross-section is depicted in Fig. 3 (bottom side). The gas temperature measurements, except the ones at $z+800$ plane, are repeated once to test for repeatability of the measurements.

Figure 3: Overview of the gas velocity (top) and temperature (bottom) measurement points at horizontal cross-sections. The position of spreader box is also shown in the pictures. The dimensions shown in the figure are in millimetres. The velocity measurements are carried out at z-375 plane while the temperature measurements are done at $z-100, z 000, z+100, z+400$, and z+800 planes.

\section{Numerical model description}

The gas-solid flow inside the cold pilot calciner is solved numerically using Barracuda Virtual Reactor $^{\circledR}$ 17.1.0. This solver has been widely used for simulation of dense and dilute gas-solid flows in different systems, e.g. circulating fluidized beds [41, 24], bubbling fluidized beds [42, 43], and coal gasifiers [22]. The numerical solver is based on an Eulerian-Lagrangian approach. In this method, the gas equations are solved in an Eulerian grid while individual groups of particles are tracked using Multi-Phase Particle-In-Cell (MP-PIC) algorithm [22]. In this section, the 
governing equations of the gas as well as solid particles are described.

\subsection{Governing equations of fluid}

In large eddy simulation, the continuity, momentum, and energy equations of the gas flow are filtered in order to resolve only the large scale structures in the flow; and instead, the effect of small scale structures is modelled. For simplicity, the filtering symbol is not shown in this paper. For a dense gas-solid flow in cold conditions and without any reactions, the conservative form of fluid continuity, momentum, and energy equations are summarized in Table 2. For the presented equations, the vector/tensor variables (and operators) are denoted as bold characters and subscript $g$ is an indication of the gas variable while $p$ subscript corresponds to the particle variable.

According to the classical Smagorinsky model for LES [44], the Smagorisky coefficient is set to a constant value of 0.1 . The filter width, $\Delta$, is equivalent to the local computational grid size. The energy containing small structures near the walls which are not resolved in the current LES simulation are instead modelled using a $k-\epsilon$ wall function model [21, 45].

Table 2: The governing equations of Eulerian-Lagrangian solution of gas-solid flow inside the pilot calciner.

\begin{tabular}{|l|l|l|}
\hline \multicolumn{2}{|l|}{ Eulerian equations of carrier fluid [37,69] } & $(1)$ \\
\hline Continuity equation & $\frac{\partial \theta_{g} \rho_{g}}{\partial t}+\nabla \cdot\left(\theta_{g} \rho_{g} \mathbf{u}_{g}\right)=0$ & $(2)$ \\
\hline Momentum equations & $\frac{\left(\partial \theta_{g} \rho_{g} \mathbf{u}_{g}\right)}{\partial t}+\nabla \cdot\left(\theta_{g} \rho_{g} \mathbf{u}_{g} \mathbf{u}_{g}\right)=-\nabla P-\mathbf{F}_{p}+\theta_{g} \rho_{g} \mathbf{g}+\nabla \cdot\left(\theta_{g} \tau_{g}\right)$ & \\
\hline Energy equation & $\frac{\left(\partial \theta_{g} \rho_{g} h_{g}\right)}{\partial t}+\nabla \cdot\left(\theta_{g} \rho_{g} h_{g} \mathbf{u}_{g}\right)=-\nabla \cdot\left(\theta_{g} P \mathbf{u}_{g}\right)-F_{T p}+\nabla \cdot\left(\theta_{g} \mathbf{u}_{g} \cdot \tau_{g}\right)-\nabla \cdot\left(-\theta_{g}^{3} \kappa_{e f f}\right.$ & $\left.\nabla T_{g}\right)$ \\
\hline
\end{tabular}




\begin{tabular}{|c|c|c|}
\hline Fluid stress tensor & $\tau_{g i j}=2 \mu_{e f f} S_{i j}-\frac{2}{3} \mu_{e f f} \delta_{i j} \frac{\partial u_{g k}}{\partial x_{k}}$ & (4) \\
\hline Fluid strain rate tensor & $S_{i j}=\frac{1}{2}\left(\frac{\partial u_{g i}}{\partial x_{j}}+\frac{\partial u_{g j}}{\partial x_{i}}\right)$ & (5) \\
\hline $\begin{array}{l}\text { Turbulent viscosity } \\
\text { [44] }\end{array}$ & $\mu_{t}=C_{S}^{2} \rho_{g} \Delta^{2}\left(S_{i j} S_{i j}\right)^{\frac{1}{2}}$ & (6) \\
\hline \multicolumn{3}{|c|}{ Lagrangian equations of particles } \\
\hline $\begin{array}{l}\text { Particle acceleration } \\
\text { [21] }\end{array}$ & $\dot{\mathbf{u}}_{p}=\frac{d \mathbf{u}_{p}}{d t}=\frac{R e_{p} C_{p}}{24 \tau_{p}}\left(\mathbf{u}_{g \odot p}-\mathbf{u}_{p}\right)-\frac{1}{\rho_{p}} \nabla P_{\odot p}+\mathbf{g}-\frac{1}{\theta_{p} \rho_{p}} \nabla \tau_{N S \odot p}$ & (7) \\
\hline Particle velocity [21] & $\mathbf{u}_{p}=\frac{d \mathbf{x}_{p}}{d t}$ & (8) \\
\hline $\begin{array}{l}\text { Particle normal stress } \\
{[21,70]}\end{array}$ & $\tau_{N S}=\frac{P_{s} \theta_{p}^{\beta}}{\max \left(\theta_{C P}-\theta_{p}, 0\right)+\varepsilon\left(1-\theta_{p}\right)}$ & (9) \\
\hline Particle temperature & $\frac{d T_{p}}{d t}=\frac{1}{2} N u_{p} \frac{T_{g \odot p}-T_{p}}{T_{T}}$ & $(10$ \\
\hline $\begin{array}{l}\text { Particle Nusselt } \\
\text { number [46] }\end{array}$ & $N u_{p}=2.0+0.6 \operatorname{Re}_{p}^{\frac{1}{2}} \operatorname{Pr}_{g}^{\frac{1}{3}}$ & (11 \\
\hline \multicolumn{3}{|c|}{ Particle-gas coupling for the grid cell $\zeta[22]$} \\
\hline $\begin{array}{l}\text { Gas-solid coupling } \\
\text { term in the momentum } \\
\text { equation }\end{array}$ & $\mathbf{F}_{\mathbf{p} \zeta}=\frac{1}{V_{\zeta}} \sum_{1}^{N_{p}} S_{\zeta, p}\left[D_{p}\left(\mathbf{u}_{g \odot p}-\mathbf{u}_{p}\right)-\frac{1}{\rho_{p}} \nabla P_{g \odot p}\right] n_{p} m_{p}$ & (12 \\
\hline $\begin{array}{l}\text { Gas-solid coupling } \\
\text { term in the energy } \\
\text { equation }\end{array}$ & $\mathbf{F}_{\mathbf{T} p \zeta}=\frac{1}{V_{\zeta}} \sum_{1}^{N_{p}} S_{\zeta, p}\left(C_{p p} \frac{d T_{p}}{d t}\right) n_{p} m_{p}$ & (13 \\
\hline
\end{tabular}




\subsection{Lagrangian equations of particles}

In the MP-PIC algorithm, solid particles are treated as computational point particles [20]. The particles belonging to each computational particle group are of the same mass, volume, velocity, location, etc. Also the number of particles in each computational particle will remain constant along the dynamic trajectories in the physical domain. The particle equations of motion and temperature change rate are also summarized in Table 2. In the acceleration equation, the right-hand side terms are the forces applied to a computational particle that are (from left to right) the drag, pressure gradient, gravity, and inter-particle collision forces, respectively.

The effect of particle-particle interactions are taken into account using the particle normal stress, $\tau_{N S}$, that is computed in the Eulerian grid. The close-pack volume fraction of particles, $\theta_{C P}$ is considered to be equal to 0.6 in this study. The particles volume fraction, $\theta_{p}$, is interpolated to the Eulerian grid from the Lagrangian information of particles position and particles volume.

The particle Nusselt number, $N u_{p}$, is calculated based on the Ranz and Marshal relation [46], valid for $R e_{p}<200$. However, the range of validity can be extended to Reynolds numbers up to 1000 [47].

\subsection{Particle-gas coupling}

The gas-solid coupling terms in the gas momentum and energy equations are also presented in Table 2 for the grid cell $\zeta$, assuming that $N_{p}$ computational particles exist inside the cell. In Eqs. (12) and (13), $n_{p}$ and $m_{p}$ are the number of real particles in each particle cloud and the mass of each particle, respectively. $V_{\zeta}$ is the cell volume, and $S_{\zeta, p}$ is the interpolation operator. 
It is worthy to mention that in the present study, for gas and particle momentum and energy equations, the mutual interactions between the particles and the flow sub-grid scales are neglected. In other words, the turbulence modulation due to the presence of particles is directly resolved for the resolved scales and neglected for the sub-grid scale flow structures. There are several studies in the literature that address the effect of turbulent flow sub-grid scales on the suspended solid particles. However, there is still no general consensus on the importance of these interactions. Wang and Squires [48] studied moderate to high Reynolds number turbulent gas-solid channel flow. They developed a model to describe the effect of sub-grid scale structures on the particles movement. They reported that the introduction of this model had a negligible effect on the particle velocity fluctuations. Other researchers have reported a reduction in the turbophoresis effect, i.e. the preferential accumulation of particles near the walls, when the sub-grid scale effects on the particles are neglected [49-52]. However, it has been reported that mean and root-mean-square values are not significantly affected by the filtered flow field [51, 52]. Nevertheless, LES without any sub-grid scale turbulent dispersion is already used in some of previous calciner simulations [27-29] and other gas-solid turbulent flows [53].

\subsection{Drag models}

For intermediate to dense gas-solid systems, the effect of particle volume fraction on the drag coefficient will become significant. Wen and $\mathrm{Yu}$ [38] included the effect of the fluid volume fraction, $\theta_{f}$, on the single particle drag. The drag coefficient proposed by Gidaspow [37] is based on the Wen-Yu drag model, which works well for dilute systems, and the Ergun drag model [54] for dense particles volume fraction. The Wen-Yu, Ergun, and Gidaspow drag coefficient correlations are summarized in Table 3. In the literature, the Gidaspow drag model has been 
widely used for numerical simulation of dilute and dense particulate systems, e.g., circulating fluidised bed riser [41], dilute pneumatic conveying [23], bubbling fluidised beds [42, 55].

Table 3: The drag correlations used in the current study.

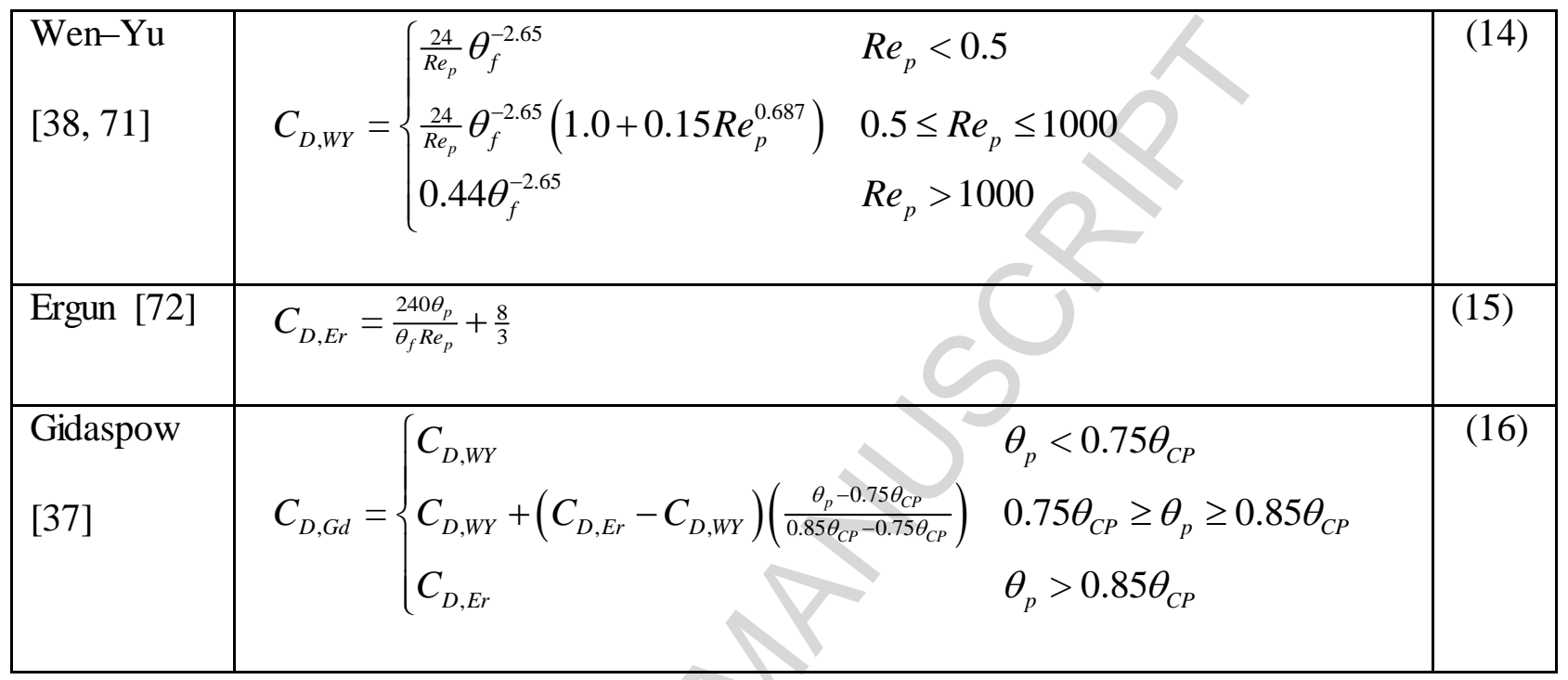

In the EMMS model, the phenomenon of meso-scale particle clustering is correlated to micro-scale single particles in dilute and dense regions, working conditions of the system at a macro-scale, particle properties, etc. [39]. In one of the early versions of the EMMS drag model [56], a drag correlation is proposed for specific operating conditions of gas-solid systems (e.g., particle mass flux, gas superficial velocity, etc.) in the fast fluidization regime. This correlation is based on the assumption that there is an inverse relation between the cluster size and the energy required for suspension and transportation [57]. In some cases, this assumption may lead to an overprediction of the cluster size and subsequently, underestimation of the true inter-phase drag force [58]. Furthermore, if the operational conditions of the gas-solid system is different from the ones that the EMMS drag model is derived based on (especially if the fluidization regime is different), the predictions of the gas-solid system might become less accurate [59]. In later 
versions of the EMMS drag model, known as EMMS/matrix scheme, a matrix of multipliers is produced according to a two-step scheme of resolving the meso-scale parameters (e.g., cluster size) at a macro-scale level, and then solving the micro-scale equations based on the meso-scale parameters $[39,60]$. As a results, the accuracy is improved due to considering the effects of meso-scale structures on micro-scales. Furthermore, the solution becomes grid-independent for coarser grids and the computational overhead is reduced [39]. The EMMS multipliers are multiplied to the drag coefficient predicted by the Wen-Yu drag model. The ratio of the drag force predicted by the EMMS model to the one predicted by Wen-Yu is referred as the Heterogeneity index, $H_{d}$, which is tabulated as a function of fluid volume fraction, $\theta_{f}$, and the magnitude of slip velocity, $U_{\text {slip }}$. The EMMS/matrix drag model is successfully applied to the dilute gas-solid systems [61-63], which is also the case for the current study.

An EMMS multiplier table is produced based on the work of Hong et al. [39, 64]. The operating conditions at which the EMMS multipliers are created are summarized in Table 4. It should be noted that the bed diameter and bed height are considered as the maximum diameter of the pilot and the calciner vessel height, respectively. The influence of these two parameters is not significant, though. The minimum gas voidage reported in this table is equivalent to the minimum gas volume fraction, $1-\theta_{C P}$, when the particles are closely packed. The particles diameter in this table is the Sauter mean diameter, $d_{S M}$, of the raw meal particles size distribution. The range of $U_{\text {slip }}$ in the table corresponds to a particle Reynolds number range of 0 to 100 . In the simulations, $H_{d}$ is interpolated from the tabulated data, and if the $\theta_{f}$ or $U_{\text {slip }}$ values are outside of the range, the boundary values are used. 
Table 4: The working conditions of the cold pilot calciner at which the EMMS multipliers for the drag model proposed by Li et al. [39] are prepared.

\begin{tabular}{|l|c|}
\hline Gas density, $\rho_{g},\left(\mathrm{~kg} \cdot \mathrm{m}^{-3}\right)$ & 1.09 \\
\hline Gas viscosity, $\mu_{g},\left(\mathrm{~kg} \cdot \mathrm{m}^{-1} \cdot \mathrm{s}^{-1}\right)$ & $1.95 \mathrm{e}-5$ \\
\hline Particle density, $\rho_{p},\left(\mathrm{~kg} \cdot \mathrm{m}^{-3}\right)$ & 2450 \\
\hline Particle diameter, $d_{S M},(\mu \mathrm{m})$ & 19.5 \\
\hline Gas superficial velocity $\left(\mathrm{m} \cdot \mathrm{s}^{-1}\right)$ & 3.397 \\
\hline Solid mass flux $\left(\mathrm{kg} \cdot \mathrm{m}^{-2} . \mathrm{s}^{-1}\right)$ & 0.361 \\
\hline Bed diameter $(m)$ & 0.7 \\
\hline Bed height $(m)$ & 1.5 \\
\hline Minimum gas voidage & \\
\hline
\end{tabular}

\section{Computational details}

The details about generation and selection of computational grids are provided in the supplementary material (section 1). In summary, four grids, grid 1 to grid 4 , are generated to study the flow in the pilot calciner. The results from grid 3 are presented to study the particle-laden flow.

For simplicity and since gas-particle interactions play a dominant role in heat transfer, the walls are considered to be adiabatic. For moderate to dense particle-laden flows, in places close to the walls, the gas boundary layer is altered by the presence of particles $[65,66]$. In the current study, as the flow is relatively dilute, a no-slip velocity boundary condition is considered for the gas phase at the walls. The effect turbulent flow near the walls is considered using a $k-\epsilon$ wall function. 
For particle-wall collisions, the normal-to-wall and tangent-to-wall momentum retention factors are set to 0.5 and 0.85 , respectively [67], corresponding to soft spheres. The effect of normal-to-wall momentum retention coefficient on the results from CPFD simulations is provided in the supplementary material (section 4). The choice of particle-wall momentum retention factors is important for systems where the interactions between particles and walls are dominating such as particle transport pipes [23]. A diffuse bounce index of 5 is chosen for the particle-wall collision meaning that particles would have a scattered angle distribution after hitting the wall. Equilibrium and isotropy collision models [68] in the CPFD solver are activated with a restitution coefficient of 0.98 . The choice of restitution coefficient is important for dense gas-solid systems as the particle-particles interactions become important.

Two inlet boundary conditions have been considered for the pilot calciner. For the hot air inlet, the air enters the calciner domain with a mass flow rate of $1.285 \mathrm{~kg} / \mathrm{s}$ and the temperature of $78^{\circ} \mathrm{C}$. This inlet gas temperature is chosen based on the averaged measured gas temperature at the plane of z-375 using the described measurement tool and for the particle-free flow. In this measurement plane, the maximum and minimum local time-averaged gas temperatures differ less than $2.5^{\circ} \mathrm{C}$ from each other. As mentioned before, the walls are considered to be adiabatic, so by choosing the inlet gas temperature based on the temperature at the upstream location of gas-solid mixing, the effect of gas heat transfer loss to the walls before mixing is considered. Also the averaged gas temperature is only reduced around $2^{\circ} \mathrm{C}$ from the measurement thermocouple at the entrance of calciner vessel (for the control system) to the z-375 plane (equivalent to almost half of the calciner height). This indicates that the wall heat transfer loss can be neglected in the simulations. The properties of the hot air boundary condition are summarized in Table 5 .

The velocity of the raw meal before entering the pilot calciner is measured by tracking 
particles structures frame by frame along the transparent raw meal pipe. The flow structures are tracked for 30 samples in total and the averaged velocity is estimated to be equal to $3.25 \mathrm{~m} / \mathrm{s}$ with a standard deviation of $0.26 \mathrm{~m} / \mathrm{s}$. It should be noted that the standard deviation accounts for both uncertainty in the velocity estimation and also fluctuations in the meal speed. The raw meal particle flow is mainly accumulated at the bottom of the slanted pipe during pilot calciner operation.

As mentioned before, the flow of raw meal in the raw meal transport pipe is not simulated. Instead, a raw meal boundary condition is considered in the spreader box geometry. This boundary condition is considered as a series of cell faces across a line in the upper face of the spreader box. An example of these cell faces (marked as red) is shown in Fig. 4 for grid 2. The raw meal particles uniformly enter the domain from these cell faces and with a direction normal to them. Using this method, it has been tried to reproduce the raw meal inlet flow as closely as possible to the real operational conditions. The inlet area for two grids (grids 2 and 3) that are studied for gas-solid cases is approximately the same and is around $1.46 \mathrm{e}-3 \mathrm{~m}^{2}$. The mass flow rate of the raw meal entering the calciner at the particle inlet is considered to be equal to $0.1389 \mathrm{~kg} / \mathrm{s}$. The gas and particles enter the pilot calciner with the same velocity of $3.25 \mathrm{~m} / \mathrm{s}$. Based on the inlet area and the gas and particles velocities at the inlet, the inlet volume fraction of particles is estimated to be equal to $1.18 \%$ and the gas mass flow rate for the raw meal boundary is equal to $5.56 \mathrm{e}-3 \mathrm{~kg} / \mathrm{s}$. The raw meal feed temperature is assumed to be equal to the average measured temperature at the meal feeding vessel, i.e. $28.5^{\circ} \mathrm{C}$. At the raw meal inlet, the gas enters with the same temperature as that of the particles. The properties of raw meal particles inlet boundary condition are also summarized in Table 5.

For defining the raw meal inlet boundary condition, a parameter called number density 
manual, $n_{p}$, is set in the solver. This parameter is a measure of the total number of computational particles based on the number of computational cells. Different values are set for this parameter as explained later.

Table 5: The summary of hot and raw meal particle inlet boundary conditions.

\begin{tabular}{|l|c|c|c|c|}
\hline & $\begin{array}{c}\text { Mass flow } \\
\text { rate }(\mathrm{kg} / \mathrm{s})\end{array}$ & Velocity $(\mathrm{m} / \mathrm{s})$ & $\begin{array}{c}\text { Temperature } \\
(\mathrm{C})\end{array}$ & $\begin{array}{c}\text { Area } \\
\left(\mathrm{mm}^{2}\right)\end{array}$ \\
\hline Hot air inlet & 1.2850 & internally & 78.0 & $7.55 \mathrm{e} 4$ \\
& & calculated & & $1.46 \mathrm{e} 3$ \\
\hline Raw meal inlet & 0.1389 & 3.25 & 28.5 & \\
\hline
\end{tabular}

The outlet boundary condition where the gas and particles leave the main vessel of the pilot calciner is set as a pressure boundary.

Figure 4: The raw meal inlet boundary condition (red colored cell faces) for grid 2 at the top surface of the spreader box.

The simulations have been carried out for different grids while the effect of some of parameters such as the number of computational particles in the domain and the selection of drag model are tested. For each simulation, the time-averaging is started after the gas-solid flow reaches quasi-steady state. The studied test cases presented here are listed in Table 6. The CPU time for 30 seconds of the time-averaging as well as the averaged number of computational particles in the domain are reported in this table. The rest of the case studies, i.e., the test cases for 
grid dependency test and the study of the dependency on the number of computational particles, are introduced and discussed in the supplementary material (sections 2 and 3).

Table 6: The simulated test cases in the present study of cold pilot calciner.

\begin{tabular}{|c|c|c|c|c|c|c|}
\hline Test case name & $\begin{array}{l}\text { Gri } \\
\text { d }\end{array}$ & $\begin{array}{l}\text { particle-lade } \\
\text { n or } \\
\text { particle-free }\end{array}$ & $\begin{array}{l}\text { Drag } \\
\text { model }\end{array}$ & $\begin{array}{c}\text { Numbe } \\
\text { r } \\
\text { density } \\
\text { manual }\end{array}$ & $\begin{array}{l}\text { Computationa } \\
1 \text { time for } 30 \mathrm{~S} \\
\text { of simulations }\end{array}$ & $\begin{array}{c}\text { Number of } \\
\text { computationa } \\
1 \text { particles }\end{array}$ \\
\hline$P F-g 3$ & $\begin{array}{c}\text { grid } \\
3\end{array}$ & particle-free & - & & $\begin{array}{c}70 \text { hrs. and } 33 \\
\text { mins. }\end{array}$ & - \\
\hline PL-g3-EMMS1 & $\begin{array}{c}\text { grid } \\
3\end{array}$ & $\begin{array}{c}\text { particle-lade } \\
n\end{array}$ & EMMS & 10,000 & $\begin{array}{c}113 \text { hrs. and } \\
18 \text { mins. }\end{array}$ & $9.334 \mathrm{e} 5$ \\
\hline $\begin{array}{c}\text { PL-g3-Gidaspow } \\
1\end{array}$ & $\begin{array}{l}\text { grid } \\
3\end{array}$ & particle-lade & $\begin{array}{c}\text { Gidaspo } \\
\text { w }\end{array}$ & 10,000 & $\begin{array}{l}144 \text { hrs. and } \\
21 \text { mins. }\end{array}$ & $1.405 \mathrm{e} 6$ \\
\hline
\end{tabular}

\section{Results and discussions}

\subsection{Study of particle-free flow}

The time-averaged contour plot of the vertical velocity component, $\mathrm{w}$, from the experiments is depicted in Fig. 5 (right). The contour is generated using MATLAB 2017a contour plot in polar coordinates. It can be seen that the $\mathrm{w}$-component of the gas velocity is not uniform at this cross-section. To the authors' knowledge, this non-uniformity in the gas velocity profile is most likely caused by a weak swirl that is created due to the hot gas pipe geometry, i.e. two elbows in the hot gas pipe, and the way that this pipe is connected to the riser. The results from particle-free flow 
simulations also show this behaviour as shown in Fig. 5 (left). The maximum velocity predicted from numerical simulation is positioned at a slightly different position compared to the measurements and the magnitude of maximum velocity is slightly over-predicted.

A quantitative comparison of the $\mathrm{w}$-component gas velocity between the CFD results (grid 3) and the measurements is presented in Fig. 6. In total, while keeping in mind that the geometry of the pilot calciner is complex especially at the connection of hot gas pipe to the riser, a reasonable agreement is found between the predicted velocity profiles and the experiments.

Figure 5: The predicted (left) and measured (right) contour plots of time-averaged upward gas velocity in the z-375 plane. The raw meal feed inlet is positioned at the top of the cross-section. The predicted contour plot corresponds to the simulation using grid 3.

Figure 6: The time-averaged profiles of vertical velocity component, w, along four lines of measured velocity at the plane of $\mathrm{z}-375$, predicted using grid 3 and compared with the experimental data.

\subsection{Study of particle-laden flow}

In this section, the gas temperature distribution in the pilot calciner is studied for the particle-laden cases along with the measurement results. The simulation results provided in this section are carried out using grid 3. For grid 2, a study regarding the dependency of the results on the number of computational particles is provided in the supplementary material (section 3).

\subsubsection{Experimental results}




\section{Visual observations}

During the particle-laden flow experiments, the particle dispersion behaviour has been studied qualitatively by visual observations of the gas-solid flow using video recording (please see the video in the supplementary materials). At regions downstream of the place where the gas-solid mixing happens, the dusty environment prevents clear observations of the flow inside the calciner. Presented in Fig. 7 is an example of the gas-solid flow in the calciner. After being fed to the calciner, the raw meal particles travel in the downward direction for a short distance until they are dragged in the upward direction by the gas flow. The maximum distance travelled by the raw meal particles in the downward direction is approximately $0.9 \mathrm{~m}$. Afterwards, the particles move as slightly dispersed clouds in the upward direction until they leave the calciner. This movement can be detected more clearly by looking at the videos taken during the experiments rather than still images. The video is provided in the supplementary material with the speed of $0.25 \mathrm{x}$. It is also possible to observe the behaviour of particle clusters toward the walls during calciner operation. Some particle clusters approaching the wall are most likely affected by the velocity boundary layer and their speed is reduced. Due to this process, they stay at their position for a short period or fall down slightly until they are dragged upward by a strong gas flow structure. The temporal near-wall accumulation of particle clusters happens mostly for the wall at the opposite side of the particle feeding pipe where the upstream gas velocity is low (see Fig. 5). Some examples of these clusters are marked in Fig. 7. Particle accumulation near the walls is also reported in previous CFD studies of calciners [27-29].

Figure 7: An instantaneous moment of the gas-solid flow inside the pilot calciner. 


\section{Gas temperature measurements}

The time-averaged gas temperature contours from experimental measurements are presented in

Fig. 8. The values of gas temperature used in this plot are averaged values for the repeated measurements. It is assumed (supported by in the simulation results in section below) that in regions with low measured gas temperature, it is likely that the particles concentration is high. Based on the measured gas temperature contours, it can be stated that after leaving the feeding pipe and the spreader box, the raw meal particles are immediately heated by the flow of hot gas and the particles that reach to the opposite side (if any) are almost heated to the gas temperature. The gas temperature is significantly decreased in the regions close to the position of the raw meal feed, especially in the z-100 plane. This can be explained by the initial movement of particles in the downward direction, providing a higher residence time for particles to exchange heat with the carrier gas. In the lower planes (i.e. $z-100, z 000$, and z+100), the dispersion of particles is limited to the regions close to the feeding position. As the particles and the gas travel upward in the calciner, the gas temperature contour becomes more uniform, implying that the particles are more uniformly dispersed. This is consistent with the visual observations of the particle dispersion. The turbulence dispersion in the gas phase contributes to this behaviour as well.

The contour plots show that the particles have a higher tendency to accumulate in the right part of the cross-section. This behaviour has been noticed during visual observations as well. The non-symmetric distribution of particles in the calciner cross-section can be explained by the non-uniform w-component gas velocity distribution in the upstream of the feeding position (see Fig. 5). The particles have a higher tendency to accumulate in regions where there is a smaller gas velocity, i.e., the right part of the cross-section in the figure. 
Figure 8: The time-averaged contours of gas temperature at planes of measurement, i.e. z-100, $\mathrm{z} 000, \mathrm{z}+100, \mathrm{z}+400$, and $\mathrm{z}+800$. The raw meal feed inlet is positioned at the top of the cross-section.

\subsubsection{Particle dispersion}

In this section, the effect of drag model on the particles aerodynamics and dispersion predicted from simulations with grid 3 is discussed. The time-averaged particle volume fraction contours predicted from CPFD model using the EMMS and Gidaspow drag models are depicted in Fig. 9 for a plane parallel to the direction of injection as well as the z-100 plane. It can be observed from this figure that in total, the predicted volume fraction of particles is higher for the Gidaspow model compared to EMMS both in dense and dilute zones. Using the Gidaspow model, the particles penetrate further in the downward direction as well as toward the wall opposite of the particle feed. Also in the z-100 plane, the central region with high particle volume fraction is more populated by particles in the simulation results from Gidaspow model. Two regions are highlighted in the volume fraction contour plot. The explanation about these regions will be given later.

In order to better quantify the particle dispersion in the calciner, the averaged particle-related parameters along the calciner height are presented in Fig. 10. All the reported values, except the mass per unit volume and the Sauter mean diameter, are weighted by the mass of numerical particles. Also these values are averaged over the cross-section for at least 90 samples of instantaneous simulation results over the simulation period with intervals of $0.25 s$. The general aerodynamic behaviour of particles in the calciner based on the EMMS and Gidaspow drag models can be addressed by considering the averaged particles volume fraction, $\left\langle\theta_{p}\right\rangle$, and the cumulative particles mass in unit volume, $\left\langle\frac{\Sigma m_{p}}{V_{\text {cell }}}\right\rangle$, shown in this figure. For both drag models, 
the particle volume fraction has a maximum at approximately $z=-0.16 m$ which is the place at which particles enter the calciner vessel after hitting the spreader box. The particle volume fraction decreases in the upstream and downstream directions because of particle dispersion in the domain. The Gidaspow drag model exhibits a higher average particles volume fraction compared to the EMMS model, especially at locations upstream of the particle inlet. The over-prediction of the particle volume fraction by the Gidaspow model compared to the EMMS model may reach to an order of magnitude.

The higher particle volume fraction predicted by the Gidaspow model affects the total mass and residence time of particles in the domain, as shown in Fig. 10. The average particle mass in unit volume, $\left\langle\frac{\Sigma m_{p}}{V_{\text {cell }}}\right\rangle$, shows a local maximum mass distribution for particles in the calciner at nearly the same location as that of the $\left\langle\theta_{p}\right\rangle$. The Gidaspow model peak shows a higher value though (around 33\% higher). Similar to the average volume fraction, the average mass of particles decreases in the upstream and downstream directions. In general, a higher value is predicted for the average mass of particles in the domain when the Gidaspow model is used.

Falling of the raw meal material in full-scale calciners through the riser to the kiln end is an unwanted behaviour that happens occasionally. Presence of particles at locations ups tream of the particle feed (by looking at particle mass) is an indication of particles falling to bottom locations of the calciner before they travel upwards and exit the calciner (also recirculation of particles may happen). The particle falling behaviour (down to the conical connection between the calciner vessel and the riser pipe) is predicted to some extent by both drag models. However, for the Gidaspow drag model, the particle mass in these regions is almost twice of that of the EMMS drag model. As mentioned previously, according to visual observations during measurements, the particles were able to travel maximum $0.9 \mathrm{~m}$ in the downward direction after being fed to the 
system. This indicates that more reasonable results for particle fall-through is predicted by the EMMS drag model, based on the results from the PL-g3-EMMS1 case.

The residence time of particles is an important parameter in operation of reactive calciner systems. As the amount of dispersed particles in the calciner is predicted differently when the Gidaspow and EMMS drag models are used, the residence times of particles, $\left\langle t_{\text {res }}\right\rangle$, would be also different. Using the Gidaspow drag model, the particles remain in the domain for a longer period especially for regions downstream of the particle feed. At the outlet of the domain, the particles residence time predicted by the Gidaspow model is around $34 \%$ higher than the one predicted by the EMMS model. The average residence time upstream of particle feed is almost the same for both models. These particles most likely have been recirculating in the upstream region and this process is repeated several times before they exit the calciner.

To clarify the size of particles present in the upstream of the particle feed, the average Sauter mean diameter of the particles is presented in Fig. 10. For both drag models, an aerodynamic separation of particles (based on size) upstream and downstream of the particle feed can be observed. This indicates that larger particles have a higher tendency to recirculate in the lower regions of the calciner. For the Gidaspow model though, this separation is significantly weaker than for the EMMS model.

Finally, the averaged Reynolds number and drag coefficients for the results from the EMMS and Gidaspow drag models are depicted in the bottom part of Fig. 10. Downstream of the particle feed position, the Reynolds number predicted by both drag models is nearly the same and it is in the range of $2-13$. In the upstream part, the particles Reynolds number predicted by the EMMS model is almost as twice as that of the Gidaspow model. This difference can be attributed to the larger particle diameter of particles in this region when the EMMS drag model is used. 
Furthermore, the differences in average slip velocity between particles and the gas may have an effect. The predicted drag coefficient is slightly higher for the EMMS model, especially in regions close to the particle feed. The higher drag force to the particles can be an indication of fast acceleration of particles by the carrier gas and subsequently low particle residence time in the system.

Figure 9: The time-averaged contours of particles volume fraction at a plane parallel to the direction of raw meal feed (top contours) and also z-100 plane (bottom contours) for two test cases of PL-g3-EMMS1 and PL-g3-Gidaspow1.

Figure 10: The averaged particle-related properties along the calciner height for two test cases of PL-g3-EMMS1 and PL-g3-Gidaspow1. With the exception of mass per unit volume and Sauter mean diameter, all values are weighted with clouds mass.

To better understand the particle behaviour in places close to the particle feed where the initial mixing happens, the scatter distribution of particles velocity and residence time are presented in Fig. 11 for two regions in z-100 plane. The two regions are marked in Fig. 9. Region-1 is placed in the center of the cross-section and contains particles that are immediately accelerated in the upward direction by the gas flow. Region- 2 corresponds to an area near the opposite wall which is also populated by particles. In the scatter plot, the symbols are a random selection of particles from at least 90 instantaneous particle fields in a way that they represent the mass distribution of particles in the area of interest. The color of each symbol represents the diameter of that particle. 
In region-1, the population of particles can be categorized into two groups. The particles belonging to group (I) have most likely a diameter below $50 \mu \mathrm{m}$. These particles are slightly accelerated by the gas flow in the upward direction and have a residence time below $1 s$. For PL-g3-EMMS1 case, nearly all particles belonging to group (I) have a positive w-component velocity and their residence time is below $0.5 s$. On the other hand, for PL-g3-Gidaspow1 case, the particles belonging to group (I) have a higher diameter and residence time as well as a smaller velocity magnitude. Some of the particles have negative velocity which may be due to the gas velocity field fluctuations when the Gidaspow model is used. Group (II) consists of particles with relatively higher $\mathrm{w}$-component velocities as well as diameters compared to group (I). These particles have nearly the same residence time range as group (I) particles and have been accelerated to a high speed most likely because of their larger diameter. When the EMMS drag model is used, the group (II) particles have a higher vertical velocity than the particles from Gidaspow model. This can be attributed to the higher drag coefficient that has been applied to the particles by using the EMMS model, as explained before. Similar to group (I), particles belonging to group (II) have a higher diameter and residence time when the Gidaspow drag model is used.

The scatter distribution of particles in region-2 is more symmetric in relation to the $w_{p}$ value, especially for the EMMS drag model. Compared to region-1, particles in this region have a higher diameter and residence time, and because of their high dynamic inertia, they have been able to travel across the cross-section to the opposite wall. In general, when the Gidaspow drag model is used, particles have a higher residence time and it is likely that particles with small diameter (below $10 \mu \mathrm{m}$ ) are also found in this region. For both drag models, the particles with both positive and negative $w_{p}$ exist in the region and particles with negative $w_{p}$ have a higher higher residence time than positive $w_{p}$ particles. This indicates that there is a tendency for particles of 
this region to be accumulated near the wall and have a high residence time. At the same time, they are recirculated slightly in that area (slow random movement of particles in the upward and downward directions) while being affected by the drag force applied to them from the gas and also the gravity force.

Figure 11: Scatter distribution of 2000 sample particles in two regions at z-100 plane and for two test cases of PL-g3-EMMS1 and PL-g3-Gidaspow1. The symbols are coloured according to the diameter of particles.

\subsubsection{Gas-solid heat transfer}

\section{Comparison of the simulation results with the experiments}

Shown in Fig. 12 are the time-averaged gas temperature contour plots at the measurement planes for the simulations with the EMMS and Gidaspow drag models and comparison with the experimental results. Furthermore, a more quantitative comparison is presented in Fig. 13 showing the time-averaged gas temperature profiles along two lines of 0 and 90 degrees in planes of measurement.

According to the contour plots in Fig. 12, for both the EMMS and Gidaspow drag models and at three planes of $\mathrm{z}-100, \mathrm{z} 000$, and $\mathrm{z}+100$ which are close to the position of the particle feed, a region of low gas temperature can be seen in the middle of the cross-section and slightly in the right side. From the experimental results, as mentioned earlier, this region is placed near to the top wall close to the raw meal feed and similar to the simulation results, it is placed asymmetrically to the right side of the cross-section. For both drag models, the shape of this cold region is similar and occupies nearly the same fraction of the cross-section. The deviation in the position of local 
low gas temperature region from the simulations compared to the measurements may be partly attributed to slight difference between the predicted velocity profiles upstreamof the measurement planes (at z-375 plane as explained earlier). Both drag models have under-predicted slightly the minimum gas temperature in the cross-section compared to the experimental results while the Gidaspow model shows a better agreement. For the results from both drag models, there is a second local minimum gas temperature near to the wall opposite of the raw meal feed. This behaviour is more pronounced for the Gidaspow drag model. This low temperature region does not exist in the measurement results.

For the planes further away from the position of the raw meal feed, i.e. $z+400$ and $z+800$, the predicted gas temperature becomes more uniform for both drag models with a tendency of a slightly lower temperature at the right side of the cross-section. The deviations between the simulation results and the measurements are reduced. Overall, considering all the studied cross-sections, the temperature gradients from the simulation results and measurements would smooth out with the same rate as the particles and the gas move in the upward direction. This indicates that the rate of particle dispersion as well as diffusion of heat are predicted correctly by the simulations.

Figure 12: The contours of time averaged gas temperature, $\left\langle T_{g}\right\rangle$, at different planes of z-100, $\mathrm{z} 000, \mathrm{z}+100, \mathrm{z}+400$, and $\mathrm{z}+800$. Comparison of experiments with the simulation results from EMMS and Gidaspow drag models. The raw meal feed inlet is placed at the top of the cross-section.

Figure 13: Comparison of the dependency of the gas time-averaged temperature on the selection 
of the drag model. The plots are for 0 and 90 degrees lines at planes of $z-100, z 000, z+100, z+400$, and $\mathrm{z}+800$ for two test cases of PL-g3-EMMS1, PL-g3-Gidaspow1. The experimental data are also shown in this plot as empty circles.

\section{Gas-solid heat transfer analysis}

As explained earlier, for simulation results of the EMMS and Gidaspow drag models, a local minimum gas temperature region exists at three planes of $z-100, z 000$, and $z+100$. This region corresponds to the particles that are moving in the upward direction and have been heated up to some extent by the gas flow upstream of the cross-section. The larger the rate of heat transfer between gas and particles upstream of this region, the higher the reduction of the gas temperature in the mentioned region. For the Gidaspow drag model compared to the EMMS model, this minimum gas temperature region is weaker (hotter) and instead in the bottom right region of the cross-section, close to the wall at the opposite side of the particle feed, another cold region exists. This second cold region is less significant for the EMMS drag model results. By comparing the averaged particles volume fraction (at z-100 plane) presented in Fig. 9 to the corresponding gas temperature contour, it can be concluded that regions with low gas temperature are significantly affected by the presence of particles.

In order to better understand the heat transfer mechanisms between the suspended particles and the carrier gas, heat transfer-related parameters for particles are depicted in Fig. 14. The averaged temperature difference between particles and the carrier gas, $\left\langle T_{g}-T_{p}\right\rangle$, is almost the same for both models. The maximum of gas-solid temperature difference happens in the region where the particles and the gas initially meet, i.e. the region between z-100 and z-300 planes. In this region, the temperature difference is slightly higher when the EMMS drag model is used. The 
averaged particles temperature, $\left\langle T_{p}\right\rangle$, is also presented in Fig. 14. As expected, the particle temperature is lowest at the place where the particles are fed to the calciner, i.e. between z-100 and z-200 planes. For the results from the EMMS drag model compared to the Gidaspow model, the average particle temperature is predicted to be higher even though the residence time for these particles is low according to Fig. 10. For some regions, this temperature difference may even reach to $8^{\circ} \mathrm{C}$. The amount of difference between the average particle temperature for EMMS and Gidaspow drag models, however, decreases as the particles move downstream until it becomes negligible at the exit of the calciner.

Also presented in Fig. 14 are the mass flow-averaged and area-averaged gas temperature along the calciner height calculated from the Eulerian field. Similar to the particle temperature, the mass flow-averaged gas temperature becomes nearly the same for both drag models at the exit of the computational domain. From the trend of mass flow-averaged gas temperature profiles, it can be stated that the heat transfer between solid particles and the gas becomes negligible approximately downstream of z500 plane for both drag models. It is worthy to mention that by performing a simple calculation for thermal equilibrium between the gas and solid particles in a steady state condition, after the completion of heat transfer, the equilibrium temperature is $72.4{ }^{\circ} \mathrm{C}$. The mass flow-averaged gas temperate at the exit of the calciner vessel is $73.2^{\circ} \mathrm{C}$ for both drag models. This indicates that the heat transfer between the gas and solid particles is not completed when the particles exit the calciner vessel (enter the swan neck).

The evolution of area-averaged gas temperature along the calciner for measurements and simulations is also presented in the bottom part of Fig. 14. The numerical results for the EMMS drag model are closer to the experimental values. The over-prediction of particle dropping to the upstream regions of the flow for the Gidaspow drag model can also be observed from the 
temperature plots. It is worth mentioning that the area-averaged values for the temperature are not necessarily the same as the mean (bulk) temperature since the velocity profile in the cross-section is not uniform.

Fig. 15 shows the temperature difference between the gas and solid particles multiplied by the mass and specific heat capacity of particle clouds per unit volume, $\left\langle\frac{\Sigma C p_{p} m_{p}\left(T_{g}-T_{p}\right)}{V_{\text {cell }}}\right\rangle$ which is called maximum thermal energy transfer term. This term can be used as a qualitative indication of local gas-solid heat transfer and is the maximum possible heat transfer between particles and the gas that can occur if the heat transfer happens instantly (the particles reach to the gas temperature with negligible travelling distance). At places close to the particle feed, this term is almost the same for both drag models but upstream and downstream of this region, the results from the Gidaspow model show a higher value. In order to take the effect of heat transfer rate into account while interpreting the above-mentioned term, one has to consider the ratio of particles Nusselt number, $N u$, to their thermal response time, $\tau_{T}$, based on eq. 10. The mentioned ratio, $\left\langle\frac{N u}{\tau_{T}}\right\rangle$, averaged with the mass of clouds, is presented in the bottom part of Fig. 14. For the EMMS and Gidaspow drag models, the $\left\langle\frac{N u}{\tau_{T}}\right\rangle$ ratio seems to be almost the same downstream of the particle feed. At the upstream of the particle feed, the predicted ratio is almost twice for the Gidaspow model compared to the EMMS model which is most likely due to the smaller size of particles.

Based on the averaged results presented in Fig. 14 and Fig. 15, it can be stated that the heat transfer between solid particles and the gas happens with a higher total rate when the Gidaspow drag model is used and especially at regions upstream and close to the particle feed. This higher heat transfer rate is mainly because of the higher population (mass) of particles in the system when the Gidaspow model is used and in turn reduces the average gas temperature as well as the solid 
temperature along the calciner. However, the final particle and gas temperatures at the exit of the pilot calciner are nearly the same for the results from both drag models. This indicates that for both drag models, the gas-solid flow reaches to a final thermal equilibrium before the particles exit the pilot calciner.

Figure 14: The averaged gas-particle temperature difference, $\left\langle T_{g \odot p}-T_{p}\right\rangle$, particle temperature, $\left\langle T_{p}\right\rangle$, and gas temperature $\left\langle T_{g}\right\rangle$ along the calciner height for two test cases of PL-g3-EMMS1 and PL-g3-Gidaspow1. The gas-particle temperature difference and particle temperature are weighted with the mass of clouds (particles) and are extracted from the Lagrangian particle field. In the bottom plot, the area-averaged and mass-flow-averaged gas temperature are calculated from the Eulerian field. The hollow circles show the area-averaged values of gas temperature obtained from the measurements.

Figure 15: The averaged gas-particle temperature difference multiplied by mass and specific heat of clouds, $\left\langle\frac{\Sigma C_{p} m_{p}\left(T_{g}-T_{p}\right)}{V_{c e l l}}\right\rangle$ and the averaged ratio of particles Nusselt number to their thermal response time, $\left\langle\frac{N u}{\tau_{T}}\right\rangle$, calculated from the Lagrangian field of particles and for two test cases of PL-g3-EMMS1 and PL-g3-Gidaspow1.

\section{Conclusions}

The gas-solid flow behaviour in a non-reacting pilot-scale calciner was studied by conducting extensive measurements and CPFD simulations using the Barracuda Virtual Reactor ${ }^{\circledR}$ software. For the particle-free flow simulations, the grid-independent velocity profiles in a plane upstream 
of the particle feed position exhibited an acceptable agreement with the measurements. During the particle-laden flow experiments, particles at the room temperature were fed to the hot gas flow in the calciner. The two drag models of EMMS and Gidaspow were considered for the simulation of this flow. The dispersion of particles in the carrier gas was studied by interpretation of the Lagrangian particle field data. When the Gidaspow model is used, there was a high amount of particles falling to the upstream regions of the calciner which was not observed during the experiments. This behaviour was less pronounced in the EMMS drag model. The gas temperature profiles predicted from simulations were compared with the measurements at different cross-sections upstream and downstream of the particle feed. The temperature profiles from both drag models had an acceptable agreement with the results from the measurements. A central low temperature region was predicted by both models and also observed from the experiments. The Gidaspow drag model predicted the approximate shape, position, and temperature value of this region more accurately than the EMMS model. However, for the Gidaspow drag model, a second low temperature region close to the opposite wall was observed which did not exist according to the measurements. Apart from this, more particle droppage to the upstream regions was predicted by the Gidaspow model which in turn led to an over-prediction of the heat transfer between the particles and the gas in the lower parts of the calciner vessel and consequent low averaged gas temperatures. The deviation of predicted area averaged gas temperatures when the EMMS model is used were up to $1.5^{\circ} \mathrm{C}$ compared to the measurements while for the Gidaspow model, this deviation may be around $50 \%$ higher. In summary, the results from the EMMS drag model were more reliable and the Barracuda Virtual Reactor ${ }^{\circledR}$ software was able to capture the solid particles dispersion and the gas-solid interactions by an acceptable accuracy. 


\section{Acknowledgements}

This study was supported within the advanced technology platform â€ $€^{\sim}$ Minerals and Cement Process Technology â€“"MiCeTechâ€ funded by the Innovation Fund Denmark, FLS midth A/S, Hempel and the Technical University of Denmark (Grant No. 39-2013-2). The authors are also grateful to Stephen Webb, Sam Clark, John Pendergrass, and other staff members of CPFD software in providing technical support. 


\section{References}

[1] Mineral commodity summaries, U.S. geological survey, https://minerals. us gs.gov/minerals/pubs/commodity/cement/170397.pdf, [accessed 08-July-2017] (1997).

[2] Mineral commodity summaries, U.S. geological survey, https ://minerals. us gs.gov/minerals/pubs/commodity/cement/mos-2017-cemen.pdf, [accessed 08-July-2017] (2017).

[3] Preheater calciner systems, FLSmidth and Co. A/S, Denmark, http://www.flsmidth.com/ /media/Brochures/Brochures\%20for\%20kilns\%20and\%20firing /Preheatercalcinersystems V2.pdf, [accessed 08-July-2017] (2011).

[4] D. K. Fidaros, C. A. Baxevanou, C. D. Dritselis, N. S. Vlachos, Numerical modelling of flow and transport processes in a calciner for cement production, Powder Technology 171 (2) (2007) 81-95. doi:10.1016/j.powtec.2006.09.011.

[5] J. I. Bhatty, F. M. Miller, S. H. Kosmatka, R. Bohan, Innovations in Portland cement manufacturing, Portland Cement Association Skokie, Ill, USA, 2004.

[6] H. Luo, Modeling the gas-solid flow in calcining furnace, Journal of Computational Multiphase Flows 3 (1) (2011) 1-12. doi:10.1260/1757-482X.3.1.1.

[7] J. L. Xie, S. X. Mei, Numerical simulation of gas-solid flow in a precalciner of cement industry, Materials Science Forum 575-578 part 2 (2008) 1234-1239.

[8] H. Mikulčić, M. Vujanović, N. Duić, Improving the sustainability of cement production by using numerical simulation of limestone thermal degradation and pulverized coal combustion in a cement calciner, Journal of Cleaner Production 88 (2015) 262-271. doi:10.1016/j.jclepro.2014.04.011. 
[9] L. Huang, J. Lu, S. Wang, Z. Hu, Numerical simulation of pollutant formation in precalciner, Canadian Journal of Chemical Engineering 83 (4) (2005) 675-684.

[10] L. Huang, J. Lu, F. Xia, W. Li, H. Ren, 3-D mathematical modeling of an in- line swirl-spray precalciner, Chemical Engineering and Processing: Process Intensification 45 (3) (2006) 204-213. doi:10.1016/j.cep.2005.09.001.

[11] D. Giddings, C. N. Eastwick, S. J. Pickering, K. Simmons, Computational fluid dynamics applied to a cement precalciner, Proceedings of the Institution of Mechanical Engineers, Part A: Journal of Power and Energy 214 (3) (2000) 269-280.

[12] S. C. Oh, D. W. Kim, J. Y. Yoon, S. J. Byun, W. T. Kwon, S. R. Kim, H. T. Kim, Numerical analysis of turbulent gas-particle flow and coal combustion in a fluidized-bed calciner, Journal of Industrial and Engineering Chemistry 10 (2) (2004) 208-214.

[13] M. Zeneli, A. Nikolopoulos, N. Nikolopoulos, P. Grammelis, S. Karellas, E. Kakaras, Simulation of the reacting flow within a pilot scale calciner by means of a three phase TFM model, Fuel Processing Technology $162 \quad$ (2017) 105-125. doi:10.1016/j.fuproc.2017.03.032.

[14] J. Ylätalo, J. Parkkinen, J. Ritvanen, T. Tynjälä, T. Hyppanen, Modeling of the oxy-combustion calciner in the post-combustion calcium looping process, Fuel 113 (2013) 770-779. doi:10.1016/j.fuel.2012.11.041.

[15] K. Atsonios, M. Zeneli, A. Nikolopoulos, N. Nikolopoulos, P. Grammelis, E. Kakaras, Calcium looping process simulation based on an advanced thermodynamic model combined with CFD analysis, Fuel 153 (2015) 371-381. doi:10.1016/j.fuel.2015.03.014.

[16] W. R. Hawthorne, The mixing of gas and air in flames; A study of diffusion and turbulent flames and their imitation in a liquid model, $\mathrm{Ph} . \mathrm{D}$. thesis, Massachusetts Institute of 
Technology, Department of Chemical Engineering (1939).

[17] M. Tosunoglu, Optimising calciner burners: Theoretical treatment of turbulent diffusion jets in cross flow, in: IEEE Cement Industry Technical Conference Record, 2007, pp. 129-139. doi:10.1109/CITCON.2007.358993.

[18] V. Mathiesen, T. Solberg, B. H. Hjertager, Predictions of gas/particle flow with an Eulerian model including a realistic particle size distribution, Powder Technology 112 (1-2) (2000) 34-45. doi:10.1016/S0032-5910(99)00303-4.

[19] M. Rizk, Mathematical modeling of densely loaded, particle-laden turbulent flows, Atomization and Sprays 3 (1) (1993) 1-27.

[20] M. J. Andrews, P. J. O'Rourke, The multiphase particle-in-cell (MP-PIC) method for dense particulate flows, International Journal of Multiphase Flow 22 (2) (1996) 379-402. doi:10.1016/0301-9322(95)00072-0.

[21] D. M. Snider, P. J. O'Rourke, The Multiphase Particle-in-Cell (MP-PIC) Method for Dense Particle Flow, Computational Gas-Solids Flows and Reacting Systems: Theory, Methods and Practice, IGI Global, 2011.

[22] D. M. Snider, S. M. Clark, P. J. O'Rourke, Eulerian-Lagrangian method for three-dimensional thermal reacting flow with application to coal gasifiers, Chemical Engineering Science 66 (6) (2011) 1285-1295. doi:10.1016/j.ces.2010.12.042.

[23] W. K. H. Ariyaratne, C. Ratnayake, M. C. Melaaen, Application of the MP-PIC method for predicting pneumatic conveying characteristics of dilute phase flows, Powder Technology 310 (2017) 318-328. doi:10.1016/j.powtec.2017.01.048.

[24] Y. Jiang, G. Qiu, H. Wang, Modelling and experimental investigation of the full-loop gas-solid flow in a circulating fluidized bed with six cyclone separators, Chemical 
Engineering Science 109 (2014) 85-97. doi:10.1016/j.ces.2014.01.029.

[25] S. Kraft, F. Kirnbauer, H. Hofbauer, Influence of drag laws on pressure and bed material recirculation rate in a cold flow model of an $8 \mathrm{MW}$ dual fluidized bed system by means of CPFD, Particuology 36 (2018) 70-81. doi:10.1016/j.partic.2017.04.009.

[26] S. Yang, H. Wu, W. Lin, H. Li, Q. Zhu, An exploratory study of three-dimensional MP-PIC-based simulation of bubbling fluidized beds with and without baffles, Particuology doi:10.1016/j.partic.2017.10.003.

[27] L. Huanpeng, L. Wentie, Z. Jianxiang, J. Ding, Z. Xiujian, L. Huilin, Numerical study of gas-solid flow in a precalciner using kinetic theory of granular flow, Chemical Engineering Journal 102 (2) (2004) 151-160. doi:10.1016/j.cej.2004.03.004.

[28] J. Zheng, Y. Wang, X. Zhu, Hydrodynamic modelling of gas and solid flows in the pre-calciner, in: Asia-Pacific Power and Energy Engineering Conference, APPEEC, 2012. doi:10.1109/APPEEC.2012.6307057.

[29] J. Zheng, H. Lu, X. Sun, Y. He, J. Ding, S. Wang, Hydrodynamic modeling of gas-particle flows in D-D calciners, Industrial and Engineering Chemistry Research 44 (9) (2005) 3033-3041. doi:10.1021/ie040168j.

[30] N. Xing, W. Zhao, Numerical simulation of the gas-solid two-phase flow in the cement precalciner based on Fluent software, Advanced Materials Research 255-260 (2011) 4232-4236. doi:10.4028/www.scientific.net/AMR.255-260.4232.

[31] X. Li, B. Ma, Z. Hu, Computational modeling of aerodynamic characteristics in sprayed and spiraled precalciner, Communications in Nonlinear Science and Numerical Simulation 13 (6) (2008) 1205-1211. doi:10.1016/j.cnsns.2006.10.002.

[32] Z. Hu, J. Lu, L. Huang, S. Wang, Numerical simulation study on gas-solid two-phase flow in 
pre-calciner, Communications in Nonlinear Science and Numerical Simulation 11 (3) (2006) 440-451. doi:10.1016/j.cnsns.2004.07.004.

[33] Z. Ghizdavet, A. Volceanov, A. Semenescu, CFD simulations of gases flow in calciners, Revista de Chimie 59 (5) (2008) 511-514.

[34] H. Mikulčić, M. Vujanović, D. K. Fidaros, P. Priesching, I. Minic, R. Tatschl, N. Duić, G. Stefanović, The application of CFD modelling to support the reduction of CO2 emissions in cement industry, Energy 45 (1) (2012) 464-473. doi:10.1016/j.energy.2012.04.030.

[35] H. Mikulčić, E. Von Berg, M. Vujanović, P. Priesching, R. Tatschl, N. Duić, Numerical analys is of cement calciner fuel efficiency and pollutant emissions, Clean Technologies and Environmental Policy 15 (3) (2013) 489-499. doi:10.1007/s10098-013-0607-5.

[36] H. Mikulčić, M. Vujanović, N. Duić, Reducing the CO2 emissions in Croatian cement industry, Applied Energy 101 (2013) 41-48. doi:10.1016/j.apenergy.2012.02.083.

[37] D. Gidaspow, Multiphase flow and fluidization: continuum and kinetic theory descriptions, Academic press, 1994.

[38] C. Y. Wen, Mechanics of fluidization, in: Chem. Eng. Prog. Symp. Ser., Vol. 6, 1966, pp. $100-111$.

[39] J. Li, W. Ge, W. Wang, N. Yang, X. Liu, L. Wang, X. He, X. Wang, J. Wang, M. Kwauk, From Multiscale Modeling to Meso-Science: A Chemical Engineering Perspective, 2013. doi:10.1007/978-3-642-35189-1.

[40] L. S. Fan, C. Zhu, Principles of Gas-Solid Flows, Cambridge Series in Chemical Engineering, Cambridge University Press, 2005.

[41] C. Chen, J. Werther, S. Heinrich, H. Y. Qi, E. U. Hartge, CPFD simulation of circulating fluidized bed risers, Powder Technology $235 \quad$ (2013) 238-247. 
doi:10.1016/j.powtec.2012.10.014.

[42] Y. Liang, Y. Zhang, T. Li, C. Lu, A critical validation study on CPFD model in simulating gas-solid bubbling fluidized beds, Powder Technology 263 (2014) 121-134. doi:10.1016/j.powtec.2014.05.003.

[43] S. Vashisth, A. H. Ahmadi Motlagh, S. Tebianian, M. Salcudean, J. R. Grace, Comparison of numerical approaches to model FCC particles in gas-solid bubbling fluidized bed, Chemical Engineering Science 134 (2015) 269-286. doi:10.1016/j.ces.2015.05.001.

[44] J. Smagorinsky, General circulation experiments with the primitive equations, Monthly Weather Review 91 (1963) 99.

[45] A. A. Amsden, T. D. Butler, P. J. O’Rourke, The KIVA-II computer program for transient multidimensional chemically reactive flows with sprays, in: SAE Technical Papers, 1987. doi:10.4271/872072.

[46] W. E. Ranz, W. R. Marshall, Evaporation from drops, Chem. Eng. Prog 48 (141) (1952) $173-180$.

[47] W. C. Macklin, Comments on the "general heat and mas s exchange of spherical hailstones", Journal of the Atmospheric Sciences 21 (2) (1964) 227-228.

[48] Q. Wang, K. D. Squires, Large Eddy Simulation of particle-laden turbulent channel flow, Physics of Fluids 8 (5) (1996) 1207-1223. doi:10.1063/1.868911.

[49] J. G. M. Kuerten, A. W. Vreman, Can turbophoresis be predicted by Large-Eddy Simulation?, Physics of Fluids 17 (1) (2005) 011701-4. doi:10.1063/1.1824151.

[50] J. G. M. Kuerten, Subgrid modeling in particle-laden channel flow, Physics of Fluids 18 (2). doi:10.1063/1.2176589.

[51] C. Marchioli, M. V. Salvetti, A. Soldati, Some issues concerning Large-Eddy Simulation of 
inertial particle dispersion in turbulent bounded flows, Physics of Fluids 20 (4). doi:10.1063/1.2911018.

[52] C. Marchioli, A. Soldati, M. V. Salvetti, J. G. M. Kuerten, A. Konan, P. Fede, O. Simonin, K. D. Squires, C. Gobert, M. Manhart, M. Jaszczur, L. M. Portela, Benchmark test on particle-laden channel flow with point-particle LES, ERCOFTAC Series 15 (2011) 177-182. doi:10.1007/978-94-007-2482-2_28.

[53] B. Lessani, M. H. Nakhaei, Large-Eddy Simulation of particle-laden turbulent flow with heat transfer, International Journal of Heat and Mass Transfer 67 (2013) 974-983. doi:10.1016/j.ijheatmasstransfer.2013.08.044.

[54] S. Ergun, Fluid flow through packed columns, Chem. Eng. Prog. 48 (1952) 89-94.

[55] J. H. Lim, K. Bae, J. H. Shin, J. H. Kim, D. H. Lee, J. H. Han, D. H. Lee, Effect of particle-particle interaction on the bed pressure drop and bubble flow by Computational Particle-Fluid Dynamics simulation of bubbling fluidized beds with shroud nozzle, Powder Technology 288 (2016) 315-323. doi:10.1016/j.powtec.2015.11.017.

[56] N. Yang, W. Wang, W. Ge, L. Wang, J. Li, Simulation of heterogeneous structure in a circulating fluidized-bed riser by combining the two-fluid model with the EMMS approach, Industrial and Engineering Chemistry Research 43 (18) (2004) 5548-5561. doi:10.1021/ie049773c.

[57] J. Li, M. Kwauk, The energy-minimization multi-scale method. metallurgical industry press (1994), 204, isbn 7-5024-1572-6.

[58] M. Zeneli, A. Nikolopoulos, N. Nikolopoulos, P. Grammelis, E. Kakaras, Application of an advanced coupled EMMS-TFM model to a pilot scale CFB carbonator, Chemical Engineering Science 138 (2015) 482-498. doi:10.1016/j.ces.2015.08.008. 
[59] V. Jiradilok, D. Gidaspow, S. Damronglerd, W. Koves, R. Mostofi, Kinetic theory based CFD simulation of turbulent fluidization of FCC particles in a riser, Chemical Engineering Science 61 (17) (2006) 5544-5559. doi:10.1016/j.ces.2006.04.006.

[60] W. Wang, J. Li, Simulation of gas-solid two-phase flow by a multi-scale cfd approach-of the emms model to the sub-grid level, Chemical Engineering Science 62 (1-2) (2007) 208-231. doi:10.1016/j.ces.2006.08.017.

[61] B. Lu, W. Wang, J. Li, Searching for a mesh-independent sub-grid model for CFD simulation of gas-solid riser flows, Chemical Engineering Science 64 (15) (2009) 3437-3447. doi:10.1016/j.ces.2009.04.024.

[62] B. Lu, W. Wang, J. Li, Eulerian simulation of gas-solid flows with particles of geldart groups A, B and D using EMMS-based meso-scale model, Chemical Engineering Science 66 (20) (2011) 4624-4635. doi:10.1016/j.ces.2011.06.026.

[63] N. Zhang, B. Lu, W. Wang, J. Li, Virtual experimentation through 3D full-loop simulation of a circulating fluidized bed, Particuology $6 \quad$ (6) (2008) 529-539. doi:10.1016/j.partic.2008.07.013.

[64] K. Hong, Z. Shi, W. Wang, J. Li, A structure-dependent multi-fluid model (sfm) for heterogeneous gas-solid flow, Chemical Engineering Science 99 (2013) 191-202. doi:10.1016/j.ces.2013.05.050.

[65] S. Jesinghausen, R. Weiffen, H. J. Schmid, Direct measurement of wall slip and slip layer thickness of non-brownian hard-sphere suspensions in rectangular channel flows, Experiments in Fluids 57 (9). doi:10.1007/s00348-016-2241-6.

[66] B. Medhi, A. Ashok Kumar, A. Singh, Apparent wall slip velocity measurements in free surface flow of concentrated suspensions, International Journal of Multiphase Flow 37 (6) 
(2011) 609-619. doi:10.1016/j.ijmultiphaseflow.2011.03.006.

[67] M. Sommerfeld, N. Huber, Experimental analysis of modelling of particle-wall collisions, International Journal of Multiphase Flow 25 (6-7) (1999) 1457-1489. doi:10.1016/S0301-9322(99)00047-6.

[68] P. J. O’Rourke, D. M. Snider, Inclusion of collisional return-to-isotropy in the MP-PIC method, Chemical Engineering Science 80 (2012) 39-54. doi:10.1016/j.ces.2012.05.047.

[69] G. K. Batchelor, A new theory of the instability of a uniform fluidized bed, Journal of Fluid Mechanics 193 (1988) 75-110. doi:10.1017/S002211208800206X.

[70] S. E. Harris, D. G. Crighton, Solitons, solitary waves, and voidage disturbances in gas-fluidized beds, Journal of Fluid Mechanics 266 (1994) 243-276. doi:10.1017/S0022112094000996.

[71] M. K. Patel, K. Pericleous, M. Cross, Numerical modelling of circulating fluidized beds, International Journal of Computational Fluid Dynamics 1 (2) (1993) 161-176. doi:10.1080/10618569308904470.

[72] R. Beetstra, M. A. Van Der Hoef, J. A. M. Kuipers, Drag force of intermediate Reynolds number flow past mono- and bidisperse arrays of spheres, AIChE Journal 53 (2) (2007) 489-501. doi:10.1002/aic.11065. 


\section{Highlights}

- We study gas-solid flow in a pilot calciner with heated air and cold particles

- Extensive measurements and CPFD simulations of the calciner are carried out

- Local gas temperature gradients are smoothed out due to particle dispersion

- CPFD simulations are in acceptable agreement with the experiments

- EMMS drag model is more accurate than the Gidaspow model 


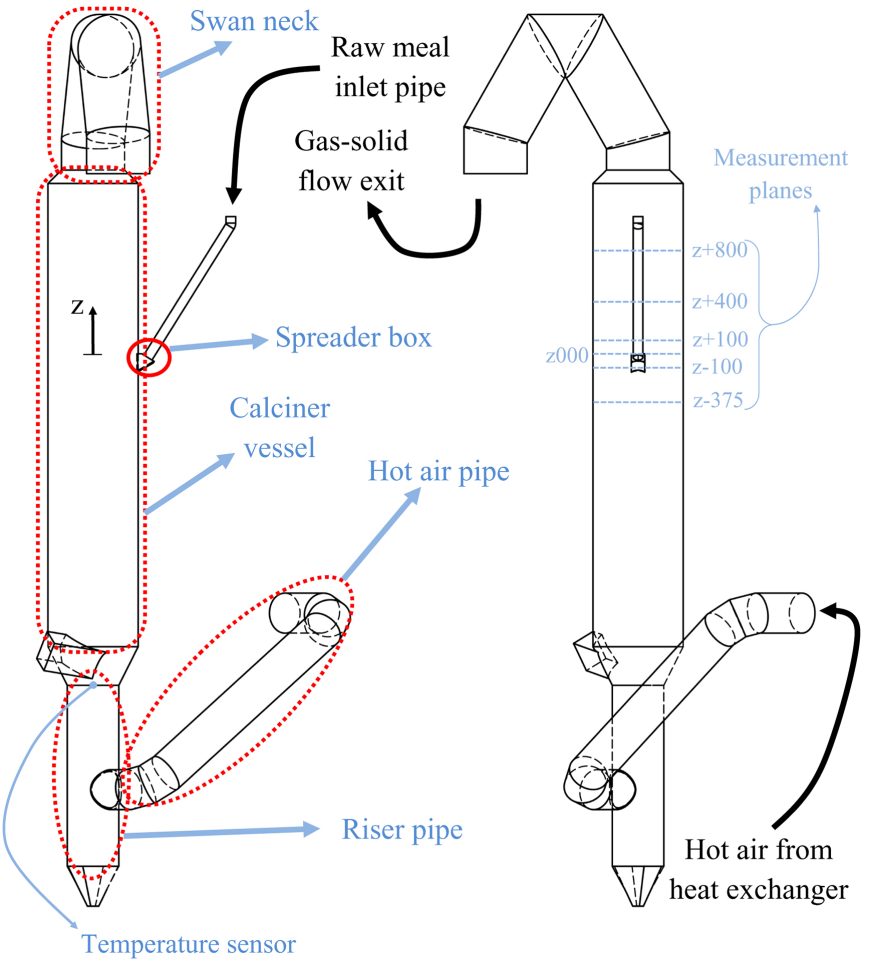

Figure 1 


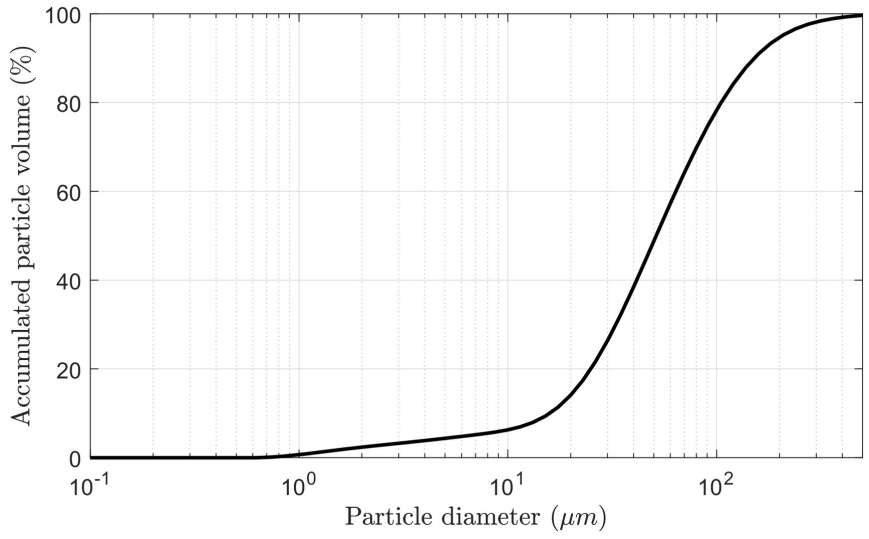

Figure 2 

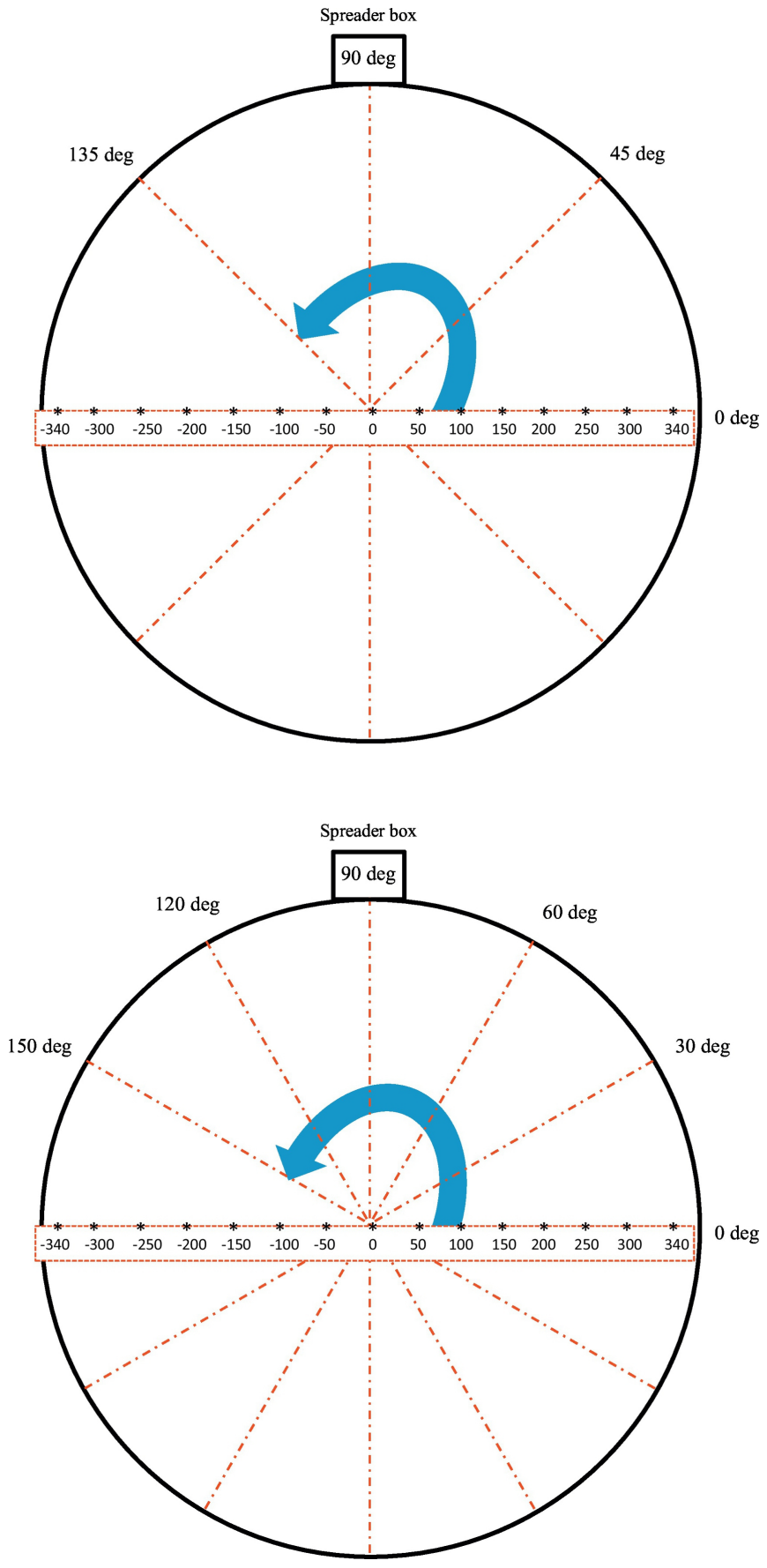

Figure 3 


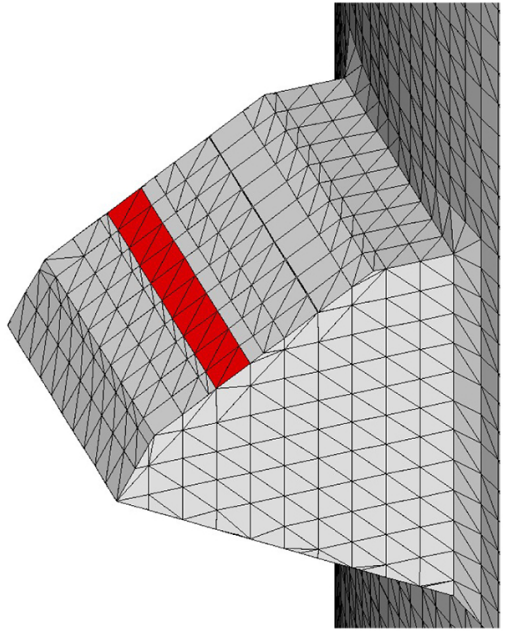

Figure 4 

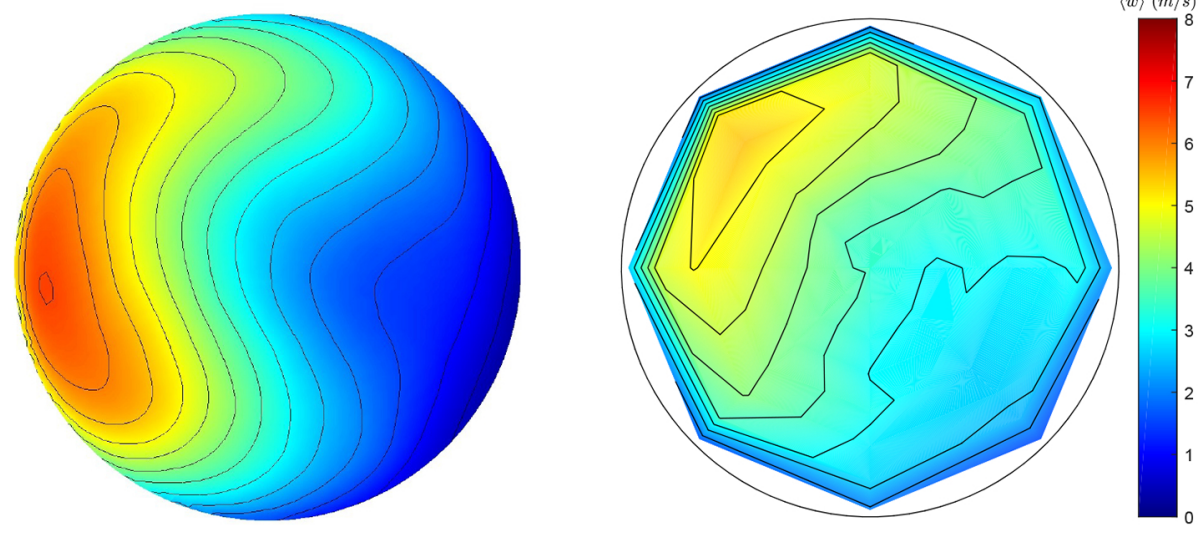

Figure 5 

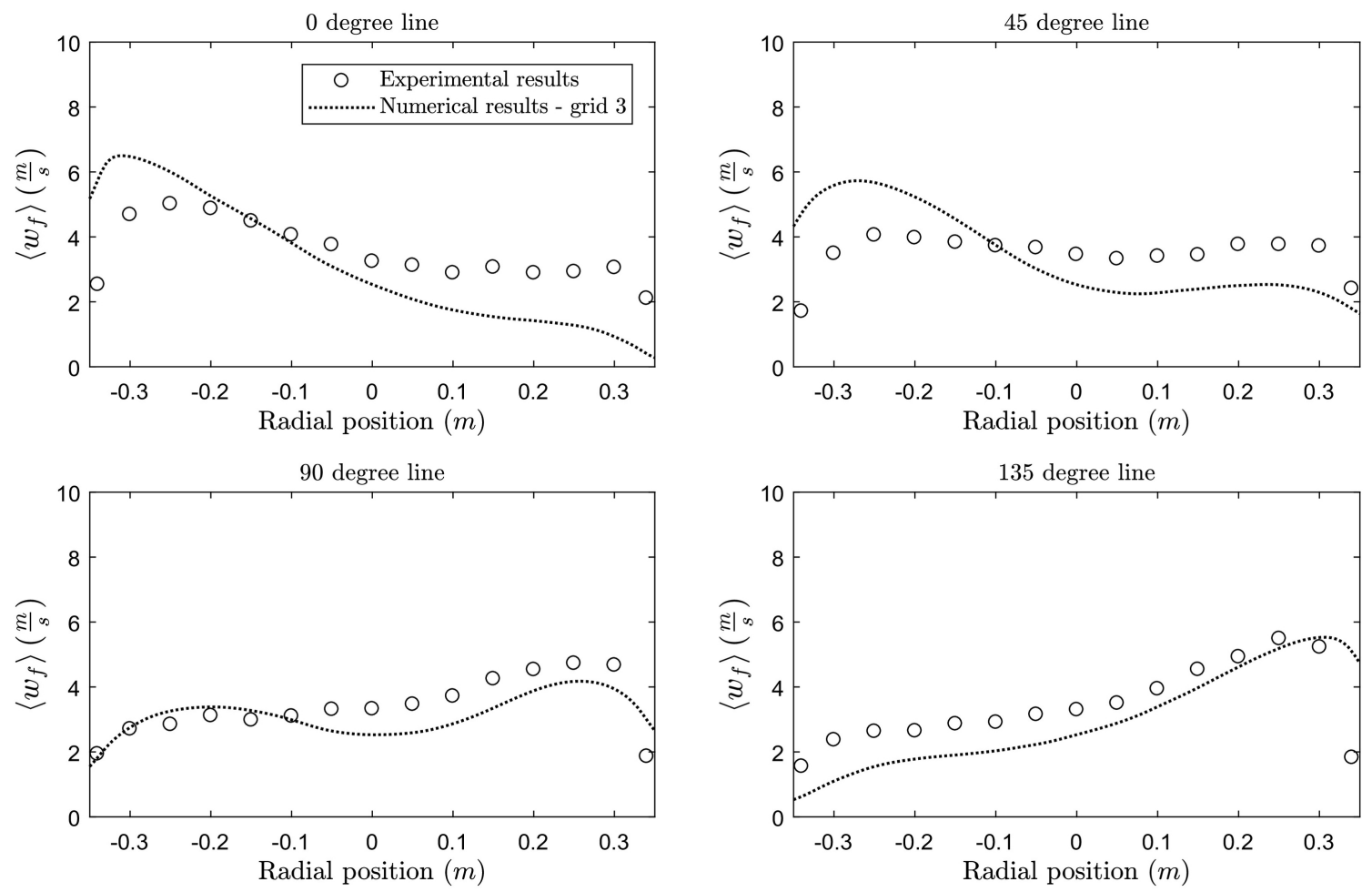

Figure 6 


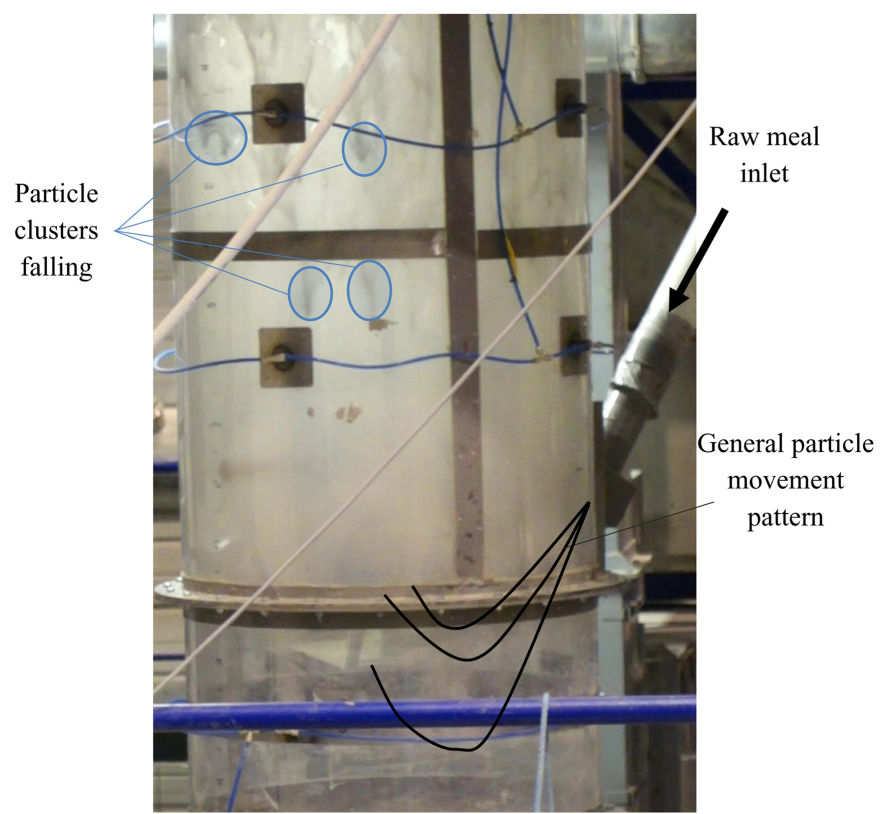

Figure 7 

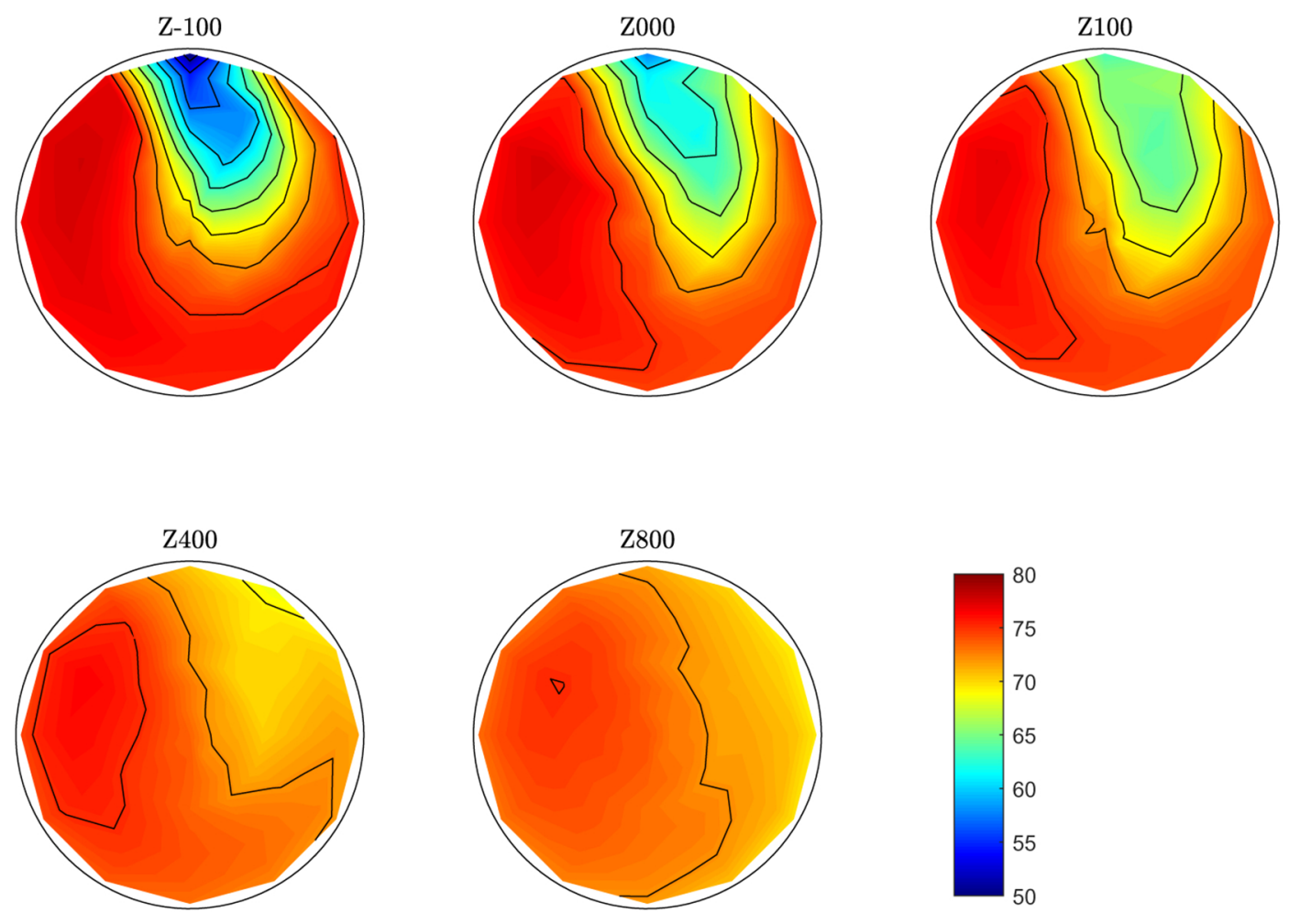

Figure 8 


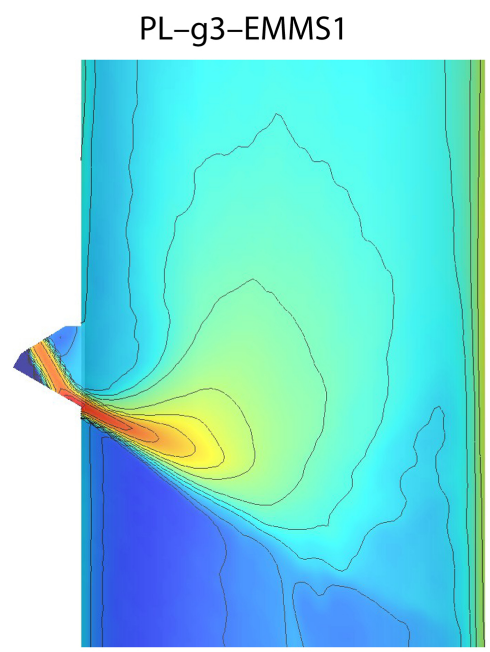

\section{PL-g3-Gidaspow1}

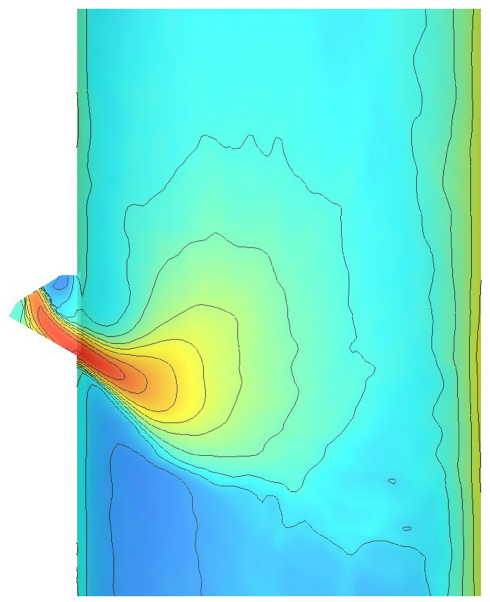

Vol. fraction
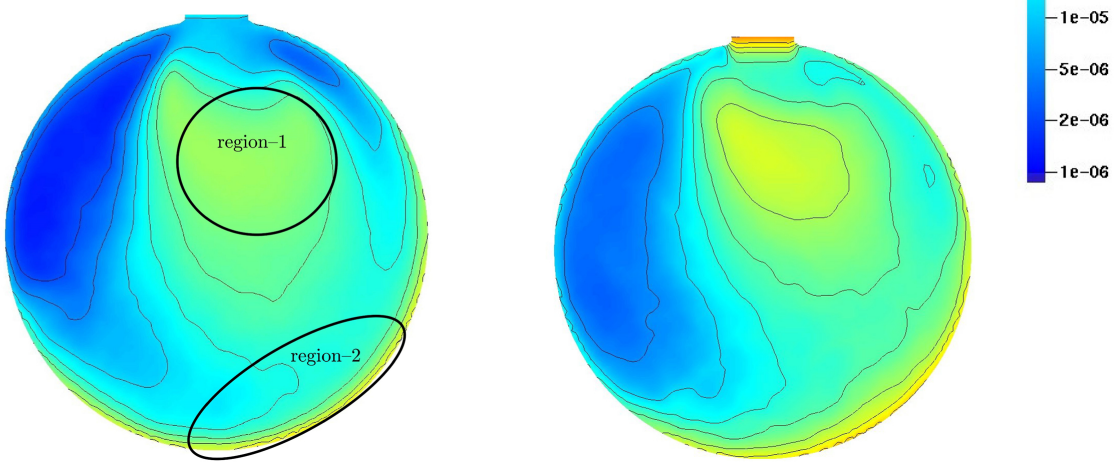

Figure 9 

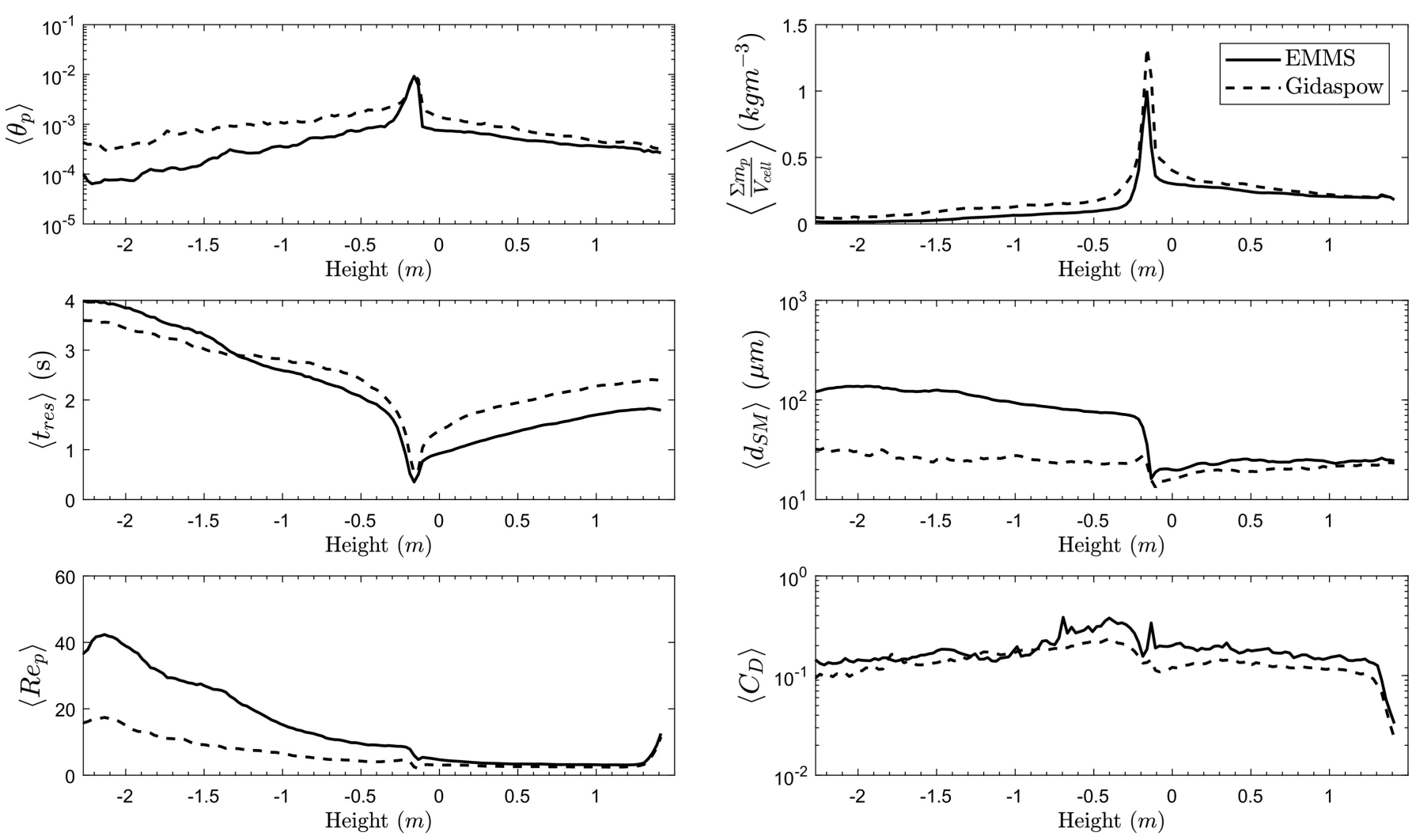

Figure 10 

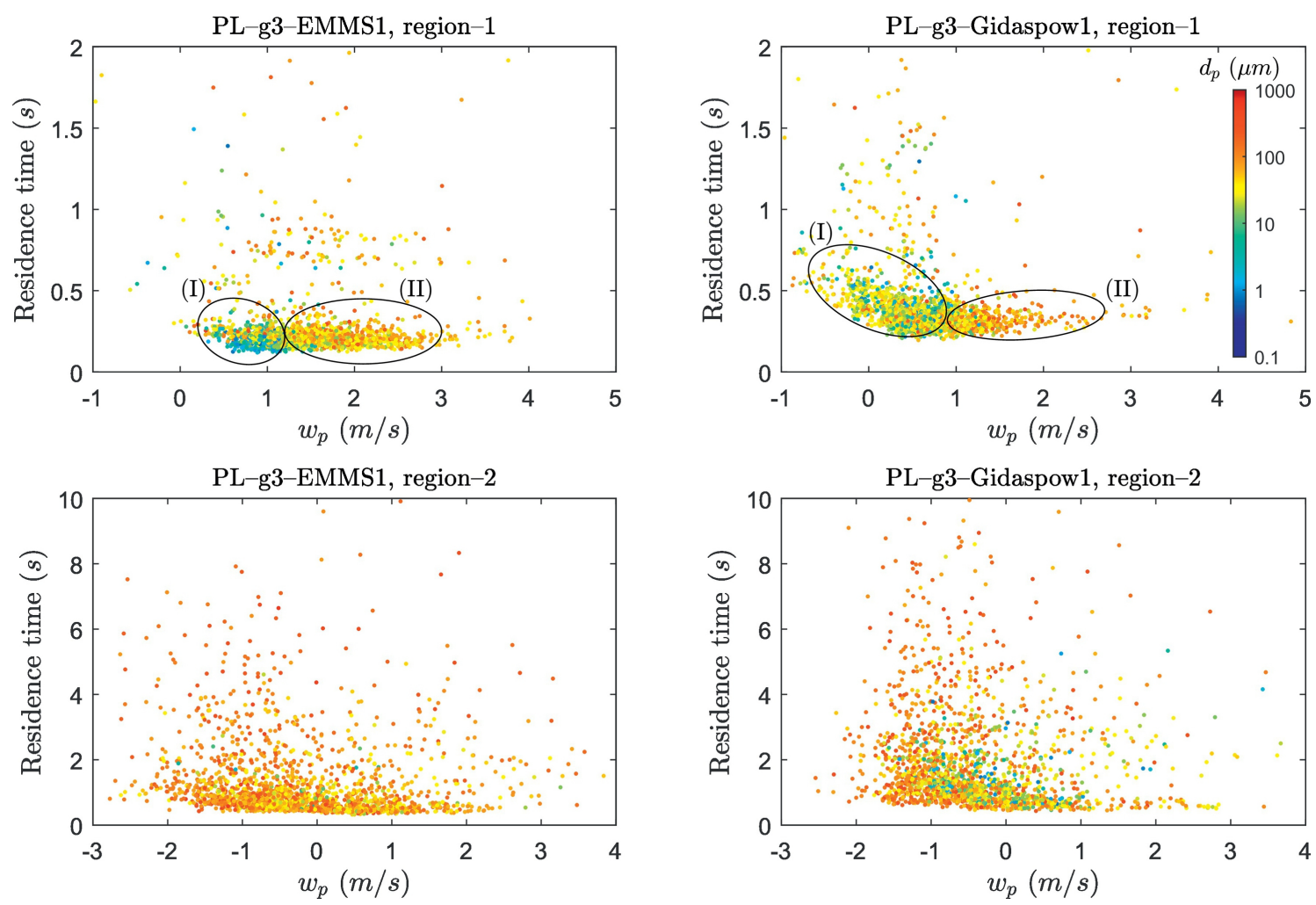

Figure 11 
PL-g3-EMMS1 PL-g3-Gidaspow1 Experiments

$$
\text { Z - } 100
$$
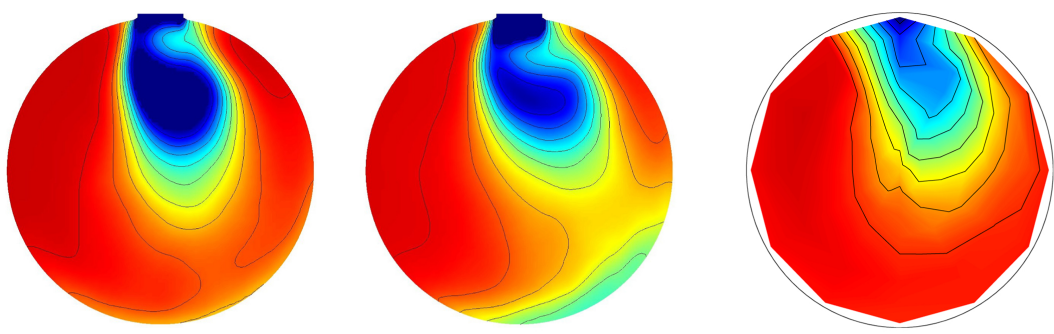

$<\mathrm{T}_{\mathrm{g}}>$
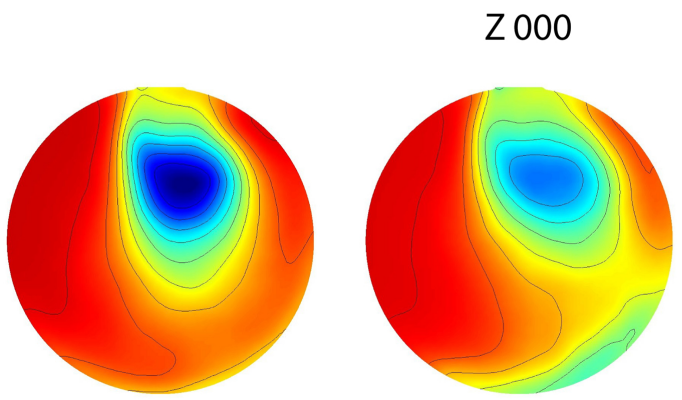

$Z+100$
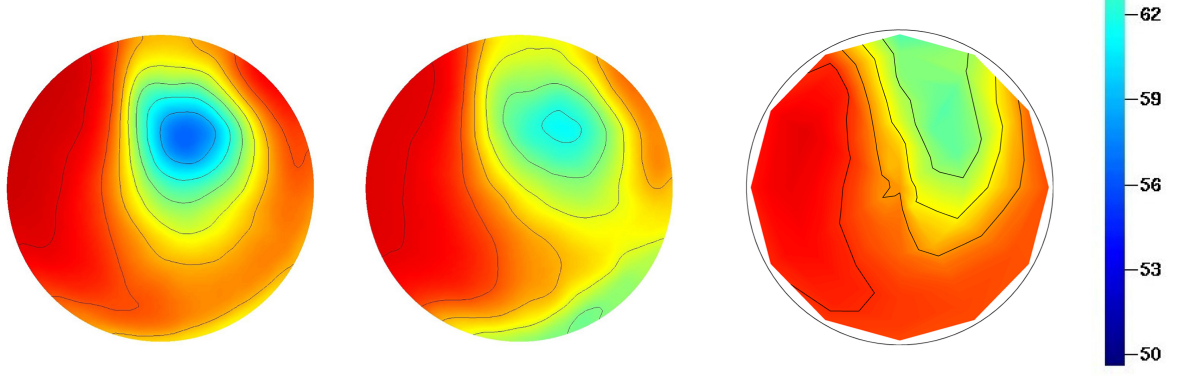

$Z+400$
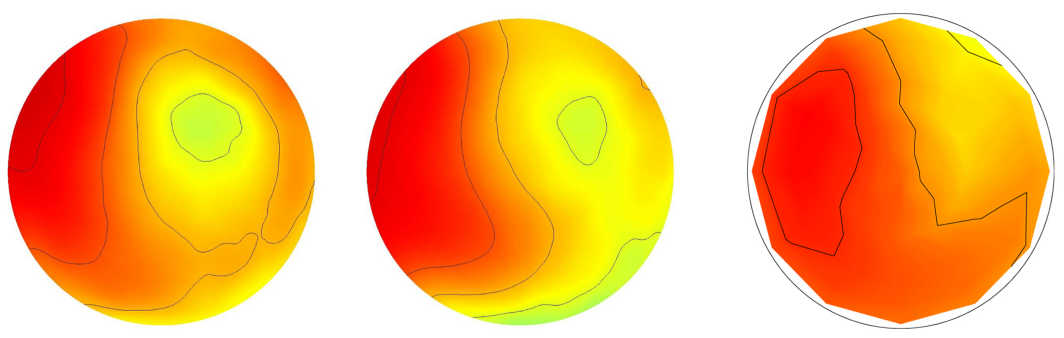

$$
Z+800
$$
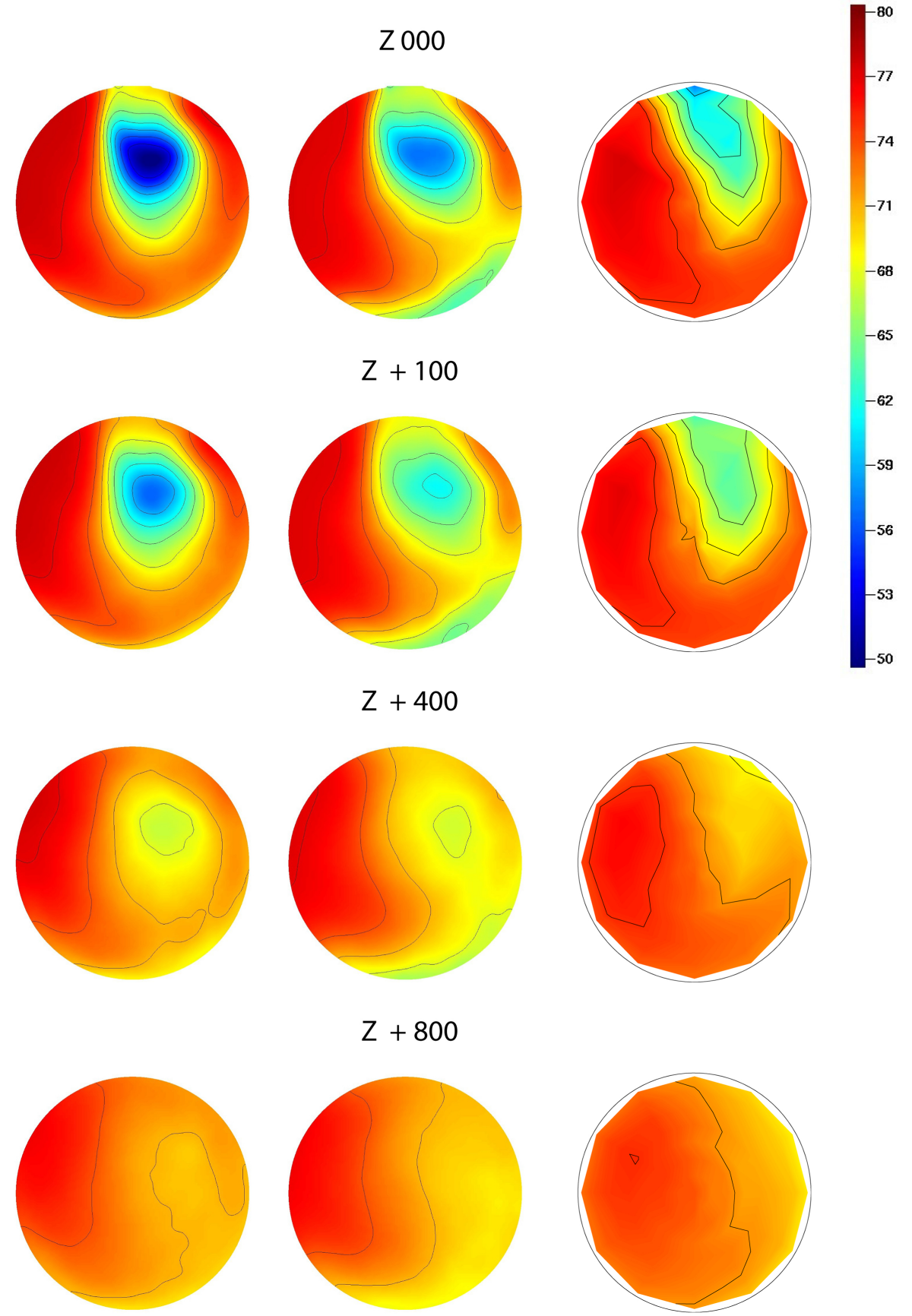

Figure 12 

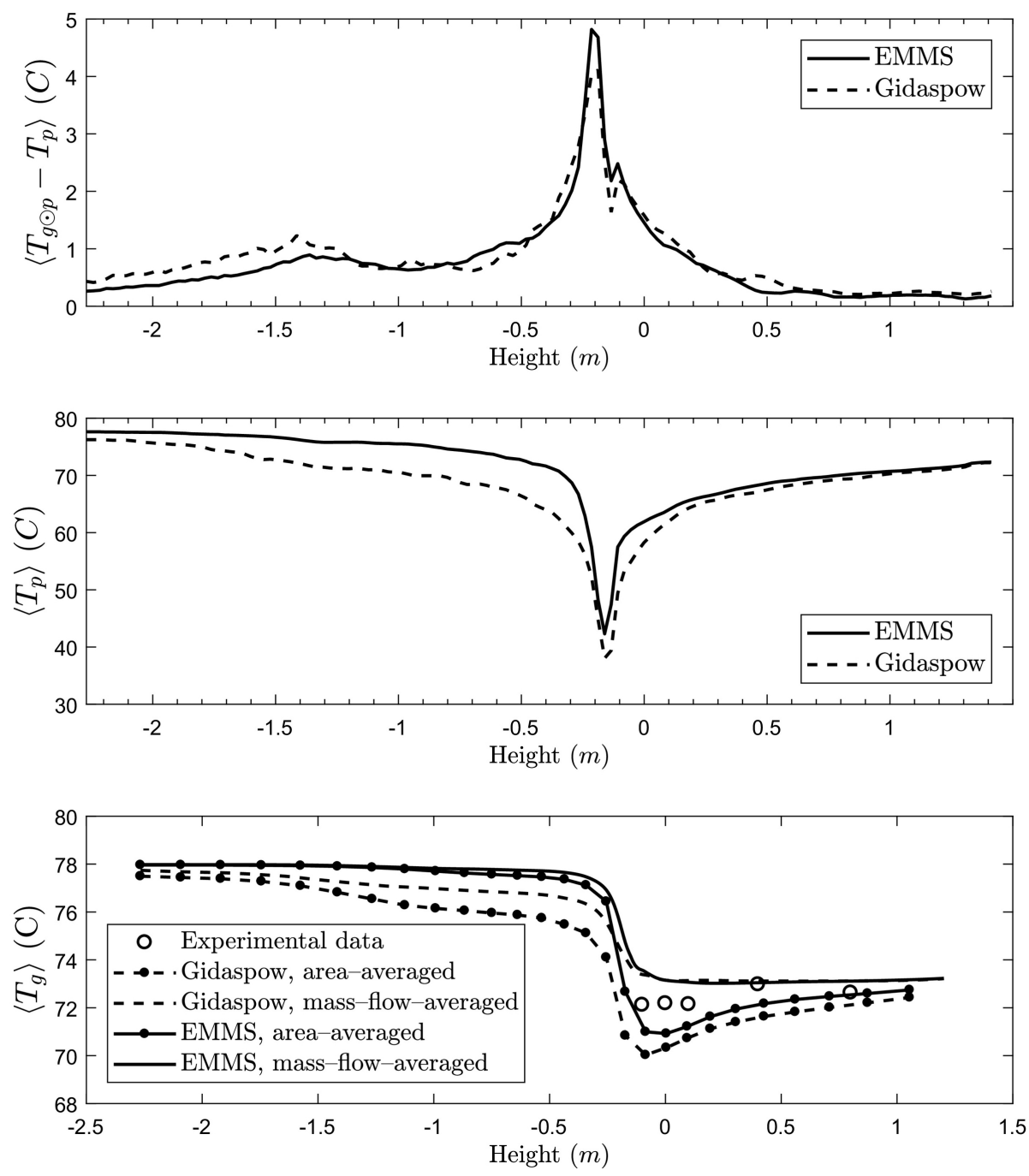

Figure 14 

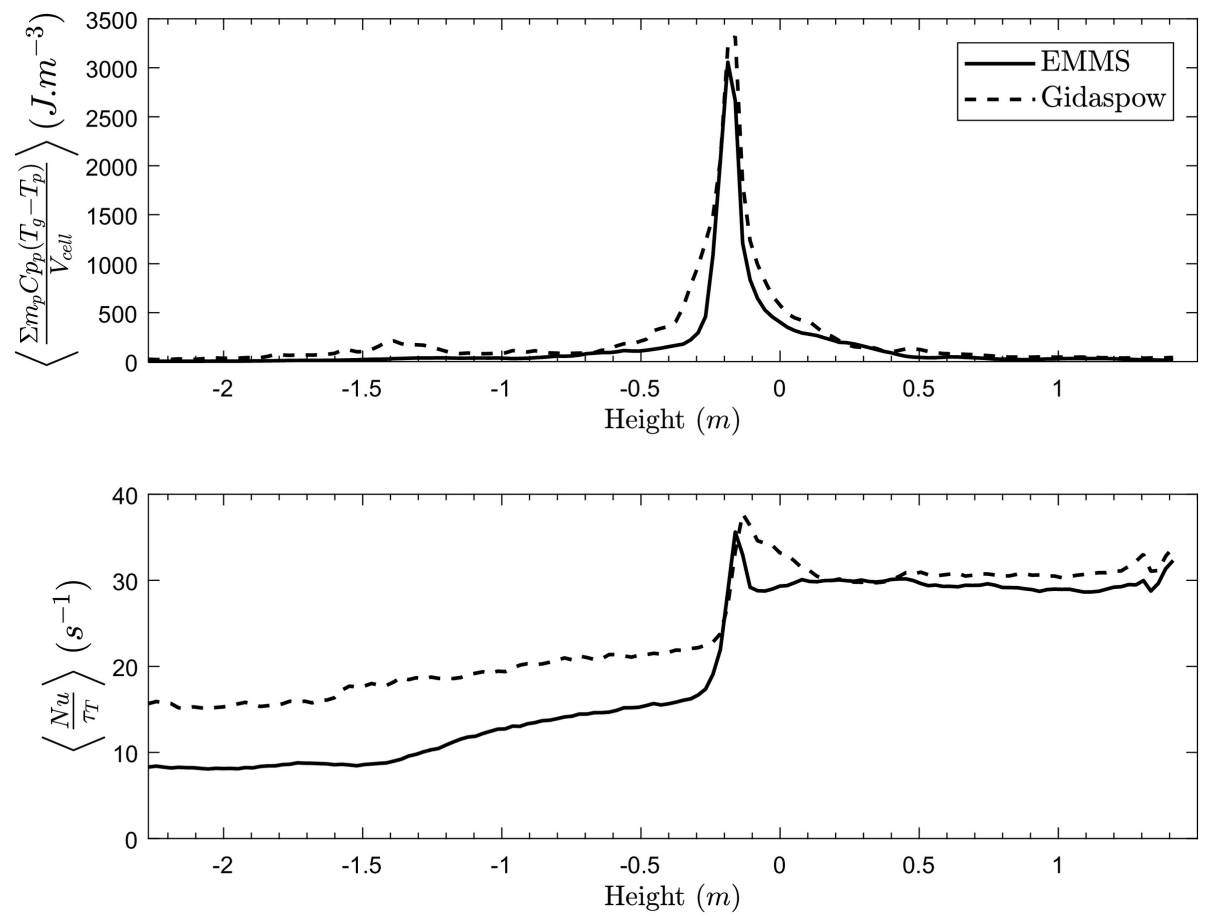

Figure 15 